\title{
Double Identification of the Optimal Hot Deformation Parameter Windows for AlCu4SiMg Alloy
}

\author{
Ying Tong ${ }^{a}$, Guo-zheng Quan ${ }^{b *}$, Jiang Zhao ${ }^{b}$, Qiao Liu ${ }^{b}$,Wei Xiong ${ }^{c}$, Rui-ju Shi ${ }^{b}$ \\ ${ }^{a}$ College of Intelligent Manufacturing and Automotive, Chongqing College of Electronic Engineering, \\ 401331, Chongqing, China \\ ${ }^{b}$ State Key Laboratory of Mechanical Transmission, School of Materials Science and Engineering, \\ Chongqing University, 400044, Chongqing, China \\ 'Institute of Nuclear and New Energy Technology, Collaborative Innovation Center of Advanced \\ Nuclear Energy Technology, Key Laboratory of Advanced Reactor Engineering and Safety of Ministry \\ of Education, Tsinghua University, 100084, Beijing, China
}

Received: February 13, 2019; Revised: April 12, 2019; Accepted: May 12, 2019

In order to achieve hot processing products with expected microstructures, the construction of corresponding relationships between micro-evolution mechanisms and hot processing parameters is essential. In this study, such corresponding relationships of as-cast $\mathrm{AlCu} 4 \mathrm{SiMg}$ alloy were constructed by double evaluating processing maps and Zener-Holloman $(Z)$ parameter maps. Based on the stressstrain data obtained from a series of isothermal compression experiments, the processing maps of $\mathrm{AlCu} 4 \mathrm{SiMg}$ alloy were constructed at the strain of $0.3,0.5,0.7$ and $0.9 \mathrm{~s}^{-1}$. The processing maps revealed that the optimal hot deformation parameter windows corresponding to dynamic recrystallization (DRX) micro-evolution mechanism mainly appear at high temperature and moderate strain rate. On the other hand, the response maps of $Z$ parameter at discrete strains were constructed, and the ideal processing windows were calibrated at the domains with relatively low $\ln Z$-value. A phenomenon was found that the optimal deformation parameter windows identified by $Z$ parameter are more conservative than those identified by processing map. By integrating processing maps and $Z$ parameter maps, the optimal processing parameter windows corresponding to DRX micro-evolution mechanism for $\mathrm{AlCu} 4 \mathrm{SiMg}$ alloy were finally obtained.

Keywords: Processing map, Dynamic recrystallization, Z parameter, Aluminum alloy.

\section{Introduction}

In common, there are three main micro-evolution mechanisms during the hot forming process of an alloy, i.e., work hardening (WH), dynamic recovery (DRV) and DRX ${ }^{1-2}$. And the DRX is a desirable micro-evolution mechanism for obtaining a hot processing component with fine microstructures and excellent mechanical properties. Thence, the identification of hot processing parameters corresponding to the desirable DRX mechanism is a critical issue.

$\mathrm{AlCu} 4 \mathrm{SiMg}$ alloy has attracted great interests in aerospace field due to its excellent combination properties of high specific strength and toughness ${ }^{3-4}$. However, the sensitivity of microstructures to hot processing parameters limited its further application. Therefore, in order to improve the workability of this alloy, it is urgent to identify the optimal hot processing parameter windows corresponding to DRX grain refine mechanism from a chaotic parameter domain. Up till now, although many investigations on thermal deformation behaviors for 2000 series aluminum alloy have been down, few researches focus on the extraction of the optimal hot processing parameters for this alloy ${ }^{5-6}$.
It is widely accepted that processing map based on dynamic material model (DMM) is an effective tool to construct the corresponding relationships between microevolution mechanisms and hot processing parameters. In addition, it is convenient to extract the recommended processing parameters corresponding to the desirable DRX micro-evolution mechanisms through thermal processing map. Up today, the basis of processing map has been successfully applied in titanium alloy ${ }^{7-8}$, aluminum alloy ${ }^{9-10}$, super alloy ${ }^{11-12}$, etc. In recent years, many scholars began paying attention to the micro-evolution mechanisms identification of alloys by processing map combined with other indicators ${ }^{13-14}$. Among such indicators, Zener-Hollomon $(Z)$ parameter, whose physical meaning is the temperature-compensated strain rate factor, is an important indicator to reflect the micro-evolution mechanism of alloys. Meysam Jafari et al. ${ }^{15}$ investigated the correlations between $Z$ parameter and necklace DRX during the hot deformation of stainless steel. Huang et al. ${ }^{16}$ found that higher $Z$-values correspond to work hardening and dynamic precipitation mechanisms in the hot deformation of 2026 aluminum alloy. Rajeshwar 
et al. ${ }^{17}$ reported that the fraction and size of DRX grains were dependent on $Z$-value. In general, the $Z$ parameter is closely related to the micro-evolution mechanisms during the thermal deformation process of alloys. However, all the above studies only investigated the $Z$-values at the peak stress or steady stress, and they ignored the effects of true strain on $Z$-values. Actually, the true strain has significant impact on the values of $Z$ parameter ${ }^{18}$. Thus, in this study, the $Z$ parameter was regarded as a variable, and the $Z$ parameter map were constructed at discrete strain. Besides, since both of the processing map and $Z$ parameter are able to identify the optimal thermal processing parameter windows, it will be scientifically significant to compare and analyze the results derived from the above two methods.

In order to extract the hot processing parameter windows corresponding to DRX micro-evolution mechanism for $\mathrm{AlCu} 4 \mathrm{SiMg}$ alloy, the hot processing maps and $Z$ parameter maps were established at the true strain of $0.3,0.5,0.7$ and 0.9 . And the DRX domains identified by processing map and $Z$ parameter were compared and discussed. Finally, the optimal hot processing parameter windows for as-cast $\mathrm{AlCu} 4 \mathrm{SiMg}$ alloy were obtained by evaluating the integrating deformation mechanism maps, which were established by superimposing the $Z$ parameter maps on hot processing maps.

\section{Basis for Processing Map}

Thermal processing map based on dynamic materials model (DMM) was firstly developed by Prasad ${ }^{19}$. According to the DMM, workpiece is essentially considered as a nonlinear dissipater of power. The total power $\mathrm{P}$ input in the system through thermal working process is dissipated in two different forms, as shown in Eq. (1). One is power dissipation content $\mathrm{G}$, which is dissipated by geometric change, the other is power dissipation co-content $\mathrm{J}$, which corresponds to micro-evolutions process such as DRX, DRV, and cracking formation, etc. ${ }^{7-8}$.

$$
\mathrm{P}=\sigma \dot{\varepsilon}=\int_{0}^{\dot{\varepsilon}} \sigma \mathrm{d} \dot{\varepsilon}+\int_{0}^{\sigma} \dot{\varepsilon} \mathrm{d} \sigma=\mathrm{G}+\mathrm{J}
$$

Where $\varepsilon$ represents strain rate and $\sigma$ represents flow stress. For a given deformation temperature and strain, $\sigma$ is the function of strain rate, as Eq. (2).

$$
\sigma=\mathrm{K} \dot{\varepsilon}^{m}
$$

Where $\mathrm{K}$ represents material constant and $m$ is strain rate sensitivity index. Due to the introduction of strain rate sensitivity index $m$, the power partitioning between $\mathrm{G}$ and J can be determined, as the following Eq. (3).

$$
m=\frac{\mathrm{dG}}{\mathrm{dJ}}=\frac{\dot{\varepsilon} \partial \sigma}{\sigma \partial \dot{\varepsilon}}=\frac{\partial \ln \sigma}{\partial \ln \dot{\varepsilon}}
$$

According to above three equations, the co-content $\mathrm{G}$ can be expressed as the following Eq. (4).

$$
\mathrm{J}=\int_{0}^{\sigma} \dot{\varepsilon} \mathrm{d} \sigma=\frac{m}{m+1} \sigma \dot{\varepsilon}
$$

As for an ideal linear power dissipation system, the value of $m$ would reach its maximum $(m=1)$, meanwhile, the value of co-content $\mathrm{J}$ would reach its maximum $\left(\mathrm{J}_{\max }\right.$ $\left.=\sigma \varepsilon^{*} / 2\right)$. In fact, for a general thermal processing system, $m$-value cannot reach its maximum. Therefore, in order to investigate the effect of $J$ on the plastic flow of material, the power dissipation coefficient $(\eta)$ is introduced, expressed as following Eq. (5).

$$
\eta=\frac{\mathrm{J}}{\mathrm{J}_{\max }}=\frac{2 m}{m+1}
$$

At a given strain, the power dissipation map can be constructed according to the variation of power dissipation coefficient $\eta$ along with temperature and strain rate. In the power dissipation map, the higher $\eta$-value is, the more power dissipated by microstructure evolution is. According to Prasad, the windows with higher $\eta$-values are usually associated with desirable restoration mechanisms such as DRV, DRX, super-plasticity, etc. On the contrary, the negative $\eta$-values are usually associated with wedge cracking and void formation. However, it is just one thing to evaluate the thermal workability of materials by $\eta$-value, another indicator to determine the thermal workability of material is Prasad instability coefficient, expressed in Eq. (6). The instability criterion has been taken into account to identify several flow instability mechanisms including local non-uniform plastic flow, adiabatic shear band and dynamic strain aging ${ }^{19}$.

$$
\xi(\dot{\varepsilon})=\frac{\partial \lg \left(\frac{m}{m+1}\right)}{\partial \lg \dot{\varepsilon}}+m
$$

In which $\xi$ represents instability coefficient. According to the instability criterion, if the values of $\xi$ are positive, the stable plastic flow will occur. On the contrary, the negative $\xi$-values represent unstable plastic flow. The instability maps can be constructed according to the variation of instability coefficient $\xi$ respect to strain rate and temperature. Finally, 
processing map can be established by superimposing instability map over power dissipation map.

\section{Material and Experiments}

The material selected in this experiment is $\mathrm{AlCu} 4 \mathrm{SiMg}$ with a detail chemical composition (wt. \%) of V $0.021, \mathrm{Cu}$ 4.47, Fe 0.23, Mg 0.58, Mn 0.49, Si 0.63, Ti 0.017, Zn 0.021 and $\mathrm{Al}$ (balance). The following experimental procedures are designed as per ASTM standard: E209-00. Twenty-one cylindrical samples with a diameter of $10 \mathrm{~mm}$ and a height of $12 \mathrm{~mm}$ were machined from the radial middle region of the as-cast homogenized cylindrical billet with a diameter of $360 \mathrm{~mm}$ and a height of $12 \mathrm{~mm}$ by wire-electrode cutting. The experiment schedule was designed as follows: twenty samples were isothermal compressed to a true strain of 0.9 under temperatures of $648 \mathrm{~K}, 673 \mathrm{~K}, 698 \mathrm{~K}, 723 \mathrm{~K}$, and 748 $\mathrm{K}$, at strain rates of $0.01 \mathrm{~s}^{-1}, 0.1 \mathrm{~s}^{-1}, 1 \mathrm{~s}^{-1}$ and $10 \mathrm{~s}^{-1}$, respectively. And the left one would not be compressed in order to observe the original microstructures. According to the original metallography, dendrites were observed clearly, as shown in fig. 1. These isothermal compression experiments were conducted on a Gleeble-3500 thermo-mechanical simulator. The direct resistance heating system in Gleeble-3500 with a thermo-coupled-feedback-controlled AC current provides rapid and precise temperature control, which can create a desired thermal profile for isothermal compression experiments. A fully integrated hydraulic servo system is capable of exerting as much as 10 tons of static force in tension or compression. Besides, the nominal stress-strain data was monitored and collected from a personal computer equipped with an automatic data acquisition system. And the true stress-strain data was derived through the following equations: $\sigma_{\mathrm{T}}=\sigma_{\mathrm{N}}\left(1-\varepsilon_{\mathrm{N}}\right)$ and $\varepsilon_{\mathrm{T}}=\ln \left(1-\varepsilon_{\mathrm{N}}\right)$, in which $\sigma_{\mathrm{T}}, \sigma_{\mathrm{N}}, \varepsilon_{\mathrm{T}}$ and $\varepsilon_{\mathrm{N}}$ represent true stress, nominal stress, true strain and nominal strain, respectively.

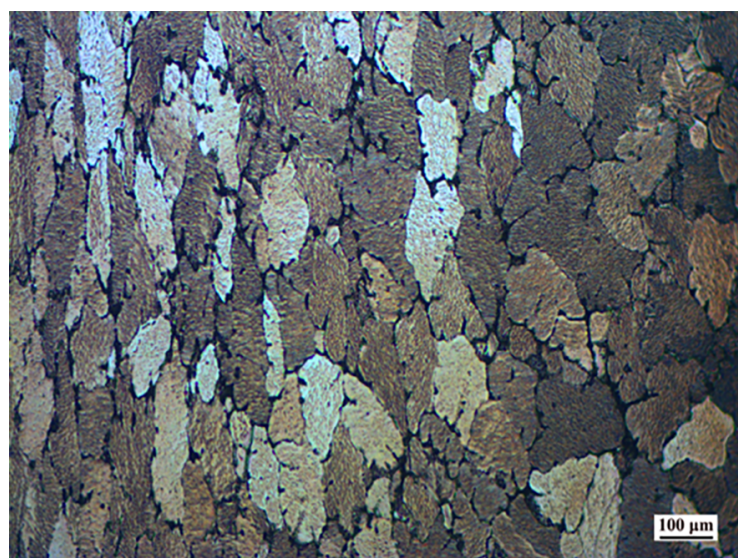

Figure 1. Original metallography for as cast $\mathrm{AlCu} 4 \mathrm{SiMg}$ alloy.
Prior to the compression experiment, two thermocouples were weld to the mid-height place of a sample. Then, the sample was placed between two anvils, meanwhile two graphite foils with a diameter of $20 \mathrm{~mm}$ serving as a lubricant were placed between the sample and anvils. The following processing routine was illustrated in fig. 2 . Firstly, the sample was heated up to a specified temperature with a heating rate of $10 \mathrm{~K} / \mathrm{s}$, and holding for $180 \mathrm{~s}$ before deformation to ensure temperature field uniform. Then, the sample was compressed at the specific temperature and strain rate with a height reduction ratio of $60 \%$, i.e. true strain of about 0.9. After that, the sample was quenched with water immediately to preserve high temperature microstructures. Such a process was repeated twenty times under various temperatures and strain rates proposed in experiment schedule.

After the isothermal compression experiments, all samples were sectioned along the compression axis. Following that, the fresh surfaces were grinded and electro-polished at $25 \mathrm{~V}$ for $20 \mathrm{~s}$ in a polishing solution composed of $48 \mathrm{ml} \mathrm{C}_{2} \mathrm{H}_{6} \mathrm{O}$ and $2 \mathrm{ml} \mathrm{HClO}_{4}$. Then, the sections of all specimens were coated with anodic film in a solution consisting of $95 \mathrm{ml} \mathrm{H}_{2} \mathrm{O}$ and $5 \mathrm{ml} \mathrm{HBF}_{4}$. Finally, the treated surfaces were observed by optical microscopy in the center zone.

\section{Results and Discussion}

\subsection{The construction of processing map}

\subsubsection{Stress-strain curves}

A series of true stress-strain curves corresponding to various forming temperatures and strain rates were exhibited in fig. 3. According to the shapes of these curves, the curves can be roughly classified into two types. One is DRX type with distinct peak stress, the other is DRV type. In fig. 3, the DRX type curves mainly associated with low strain rate and high deformation temperature, such as strain rate of 0.1 $\mathrm{s}^{-1}$ and temperature of $723 \mathrm{~K}$. As for the DRX type curves, three distinct stages can be observed. At the first stage with a small true strain, the flow stress increases rapidly due to the formation of poorly developed sub-grain boundaries and the increment of dislocation density i.e. the occurrence of WH. At the second stage, the intensity of work hardening decreases due to dynamic softening mechanisms happening. When flow stress increasing to a peak value, it begins to decrease monotonically to third stage where the effects of work hardening and dynamic softening reaches a dynamic equilibrium. In general, the stress is sensitively dependent on the hot deformation parameters including strain rate, temperature and strain. 


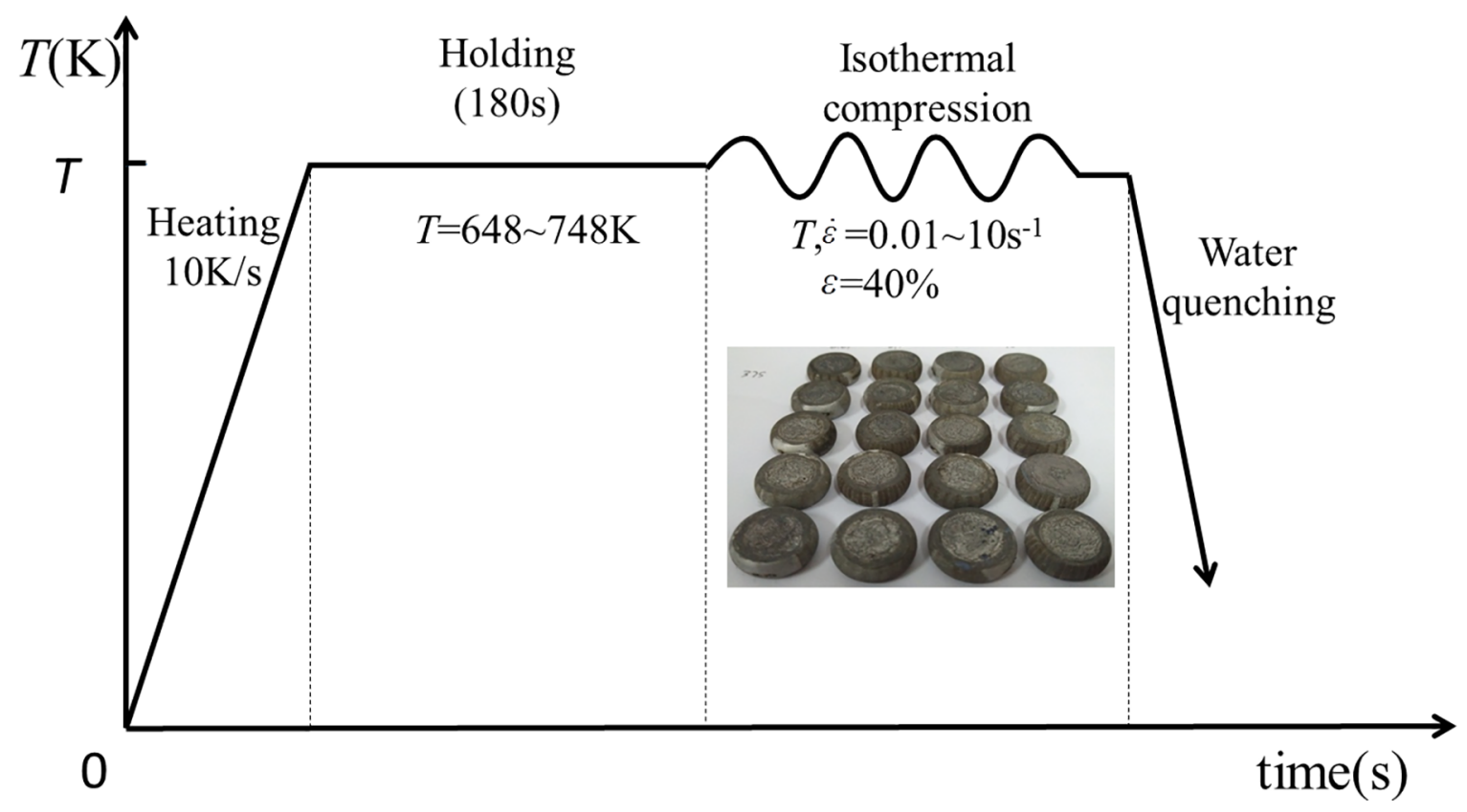

Figure 2. Processing routine illustration of isothermal compression experiment.

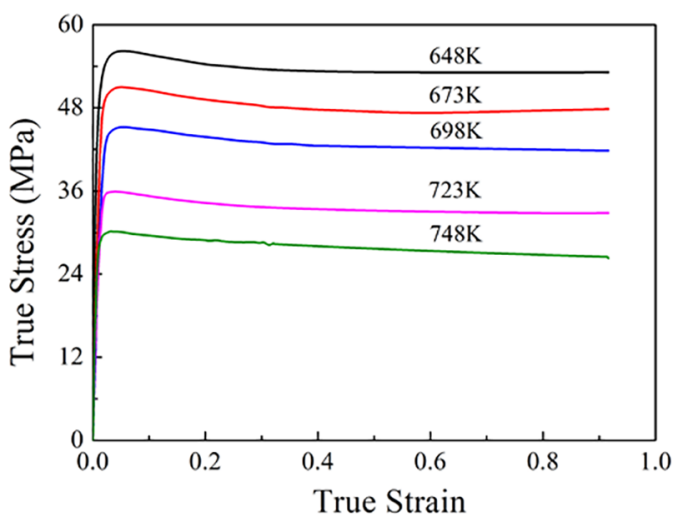

(a)

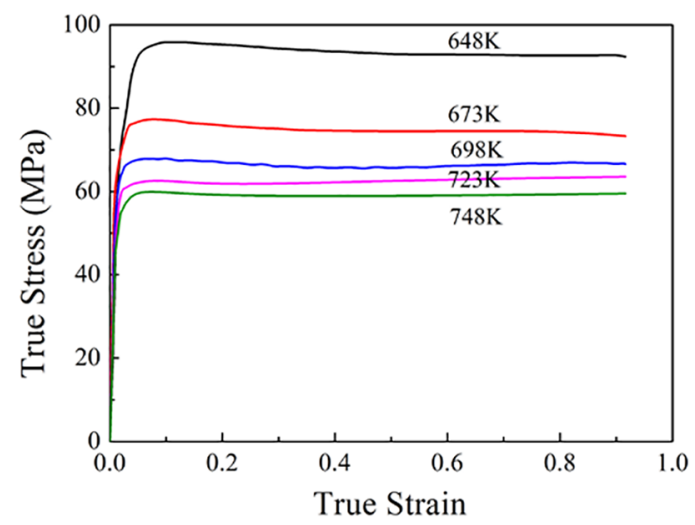

(c)

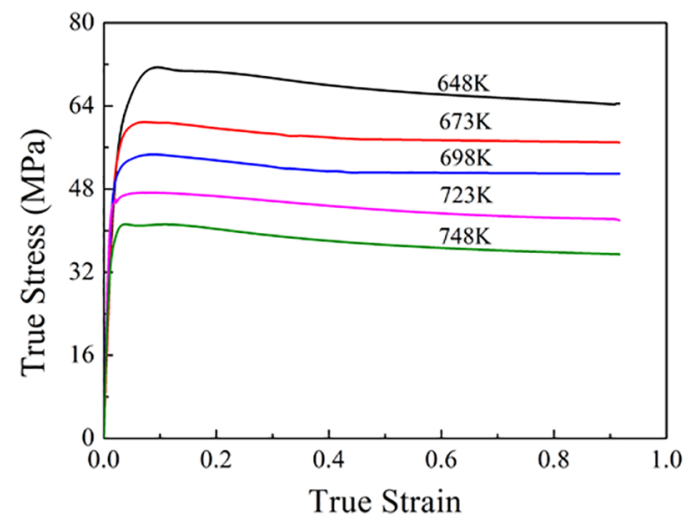

(b)

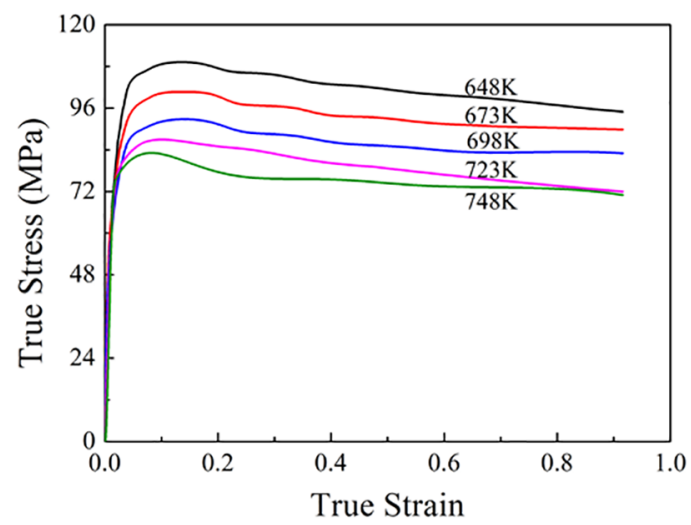

(d)

Figure 3. True stress-strain curves for as-cast AlCu4SiMg alloy at strain rate of (a) $0.01 \mathrm{~s}^{-1}$, (b) $0.1 \mathrm{~s}^{-1}$, (c) $1 \mathrm{~s}^{-1}$ and (d) $10 \mathrm{~s}^{-1}$. 


\subsubsection{Strain rate sensitivity $\mathrm{m}$}

The strain rate sensitivity, $m$, is a parameter applied to reflect the sensitivity of flow stress on strain rate. It is an important bridge to link the internal workability of materials and thermal deformation parameters. For a general aluminum alloy, the range of $m$ is from 0.02 to 0.2 . While for superplastic alloy, $m$-values vary in the range of 0.3 to 0.9 . In order to show the corresponding relationships between strain rate sensitivity $m$ and thermal processing parameters such as temperature and strain rate, the $m$-values for $\mathrm{AlCu} 4 \mathrm{SiMg}$ alloy were derived by calculating the slope of the fitted cubic splines (shown as fig. 4) for $\lg \sigma$ verses $\lg \varepsilon$ at constant temperatures and true strains. And the $m$-values under various deformation conditions were recorded in table 1. According to table 1, it can be found that there are several negative $m$-values under the following conditions: true strain of $0.3-0.9$, temperature of $648 \mathrm{~K}$ and strain rate of $10 \mathrm{~s}^{-1}$; true strain of $0.5-0.9$, temperature of $748 \mathrm{~K}$ and strain rate of $10 \mathrm{~s}^{-1}$; true strain of $0.7-0.9$, temperature of $723 \mathrm{~K}$ and strain rate of $10 \mathrm{~s}^{-1}$; true strain of 0.9 , temperature of $748 \mathrm{~K}$ and strain rate $0.01 \mathrm{~s}^{-1}$, respectively. According to Prasad, negative $m$-values correspond to the unstable plastic deformation such as formation of adiabatic shear band (ASB), dynamic strain aging (DSA), deformation twinning, and the growth of micro-cracks. Generally, the $m$-value varies irregularly with strain, strain rate and temperature. In order to clearly show the detail response relationships between $m$-values and thermal deformation conditions, the thermal processing parameters and $m$-values were interpolated and the response surfaces were plotted in fig. 5. According to fig. 5 , at true strain of $0.3,0.5,0.7$ and 0.9 , two local maximum $m$-values appear at the domains around forming temperature of $648 \mathrm{~K}$, strain rate of $0.1 \mathrm{~s}^{-1}$ and temperature of $748 \mathrm{~K}$, strain rate of $0.1 \mathrm{~s}^{-1}$. At the strain rate of $10 \mathrm{~s}^{-1}$ and $0.01 \mathrm{~s}^{-1}$, the $m$-values are relatively low. Comparing fig. 5(a)-(d) with one and each other, it can be found that the shapes of these response surfaces become more and more prominent with the increasing strain.

Since the variation of $m$-values represents the transition of different micro-evolution mechanisms, it is necessary to introduce the possible micro-evolution mechanisms for $\mathrm{AlCu} 4 \mathrm{SiMg}$ alloy. Under the experimental temperature of 648-748 K, the crystal structure of AlCu4SiMg alloy is face-centered cubic (FCC) structure. For a material with FCC structure, the full family of slip systems can be written as $\langle 110>\{111\}$, and twelve slip systems (four slip planes with three directions) coexist. According to dislocation movement theory, basal slip will be activated firstly at low temperature. In other word, perfect edge dislocations tend to move on basal planes (the most densely packed planes), along the closest packed directions. It is an athermal slip mode which will not change the $m$-values. With temperature increasing, another slip mode, non-basal slip is thermally activated. It is a diathermal slip mode which will lead to the $m$-values increase greatly. In fact, at elevated temperature, perfect edge dislocations slip on basal planes will tend to translate into partial dislocation slips on dynamically derived slip planes. From the energy point of view, the decomposition reactions of dislocation are always favored, since the line energy of dislocation will be dispersed when a perfect dislocation with concentrated line energy translate into two partial dislocations, albeit a new staking fault will be generated. Therefore, the non-basal slips contribute to $m$-values increasing. Generally, DRV or DRX will easily occur at high $m$-values because non-basal slip increases the density of dislocation, which provides advantageous conditions for the formation of sub-structure. During the thermal deformation of $\mathrm{AlCu} 4 \mathrm{SiMg}$ alloy, various thermal deformation mechanisms coexist, and have a synergism influence on the variation of $m$-values.

\subsubsection{Power dissipation coefficient $\eta$}

In order to further investigate the correlations between thermal deformation mechanisms and hot processing parameters, power dissipation coefficient $\eta$, a dimensionless parameter, was introduced. It represents the relative rate of entropy production in thermal deformation. According to the calculating method introduced in section 2 , the $\eta$-values under various deformation temperatures and strain rates can be obtained, and the power dissipation maps at true strain of $0.3,0.5,0.7$ and 0.9 has been plotted in fig. 6. In fig. 6, the numbers on each contour line represent the $\eta$-values, which reflect the extent of microstructural evolutions during a thermal deformation process. Generally, the higher $\eta$-values mean more power dissipated in the form of microstructural evolutions, usually including DRX or DRV softening mechanisms. According to the prior researches, $\eta$-values varying in the range of 0.2-0.3 are corresponding to DRV mechanism, while $\eta$-values above 0.3 are corresponding to DRX mechanism ${ }^{19}$. Hence, it can be summarized that the power dissipation maps with contour lines reflect the dynamic micro-evolution process of $\mathrm{AlCu} 4 \mathrm{SiMg}$ alloy during a thermal deformation process. According to fig. 6 , it can be found that there are several black regions with negative $\eta$-values, and these regions represent unstable plastic flow. In fact, the negative $\eta$-values are originated from the negative $m$-values. Comparing these power dissipation maps at true strain of $0.3,0.5,0.7$ and 0.9 with one and each other, it can be found that the level of $\eta$-values varies considerably with strain increasing. In fig. $6(\mathrm{a})$, at true strain of 0.3 , there are three domains with higher $\eta$-values $(>0.2)$ as follows: temperatures $648-658 \mathrm{~K}$ and strain rate $0.1-1 \mathrm{~s}^{-1}$, temperatures 673-723 $\mathrm{K}$ and strain rate 1-10 $\mathrm{s}^{-1}$, temperatures 723-748 $\mathrm{K}$ and strain rate $0.01-10 \mathrm{~s}^{-1}$. In fig. $6(\mathrm{~b})-(\mathrm{d})$, there are two domains with higher $\eta$-values as follows: temperatures 648-658 $\mathrm{K}$ and strain rate $0.1-1 \mathrm{~s}^{-1}$, temperatures $723-748$ $\mathrm{K}$ and strain rate $0.01-1 \mathrm{~s}^{-1}$. According to the distribution 

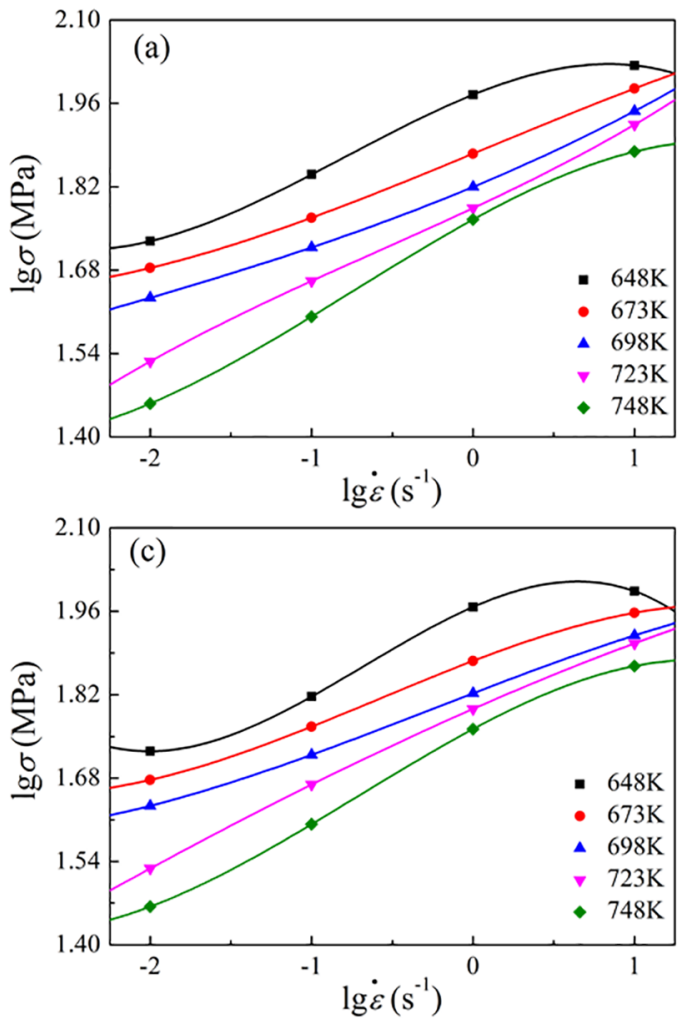
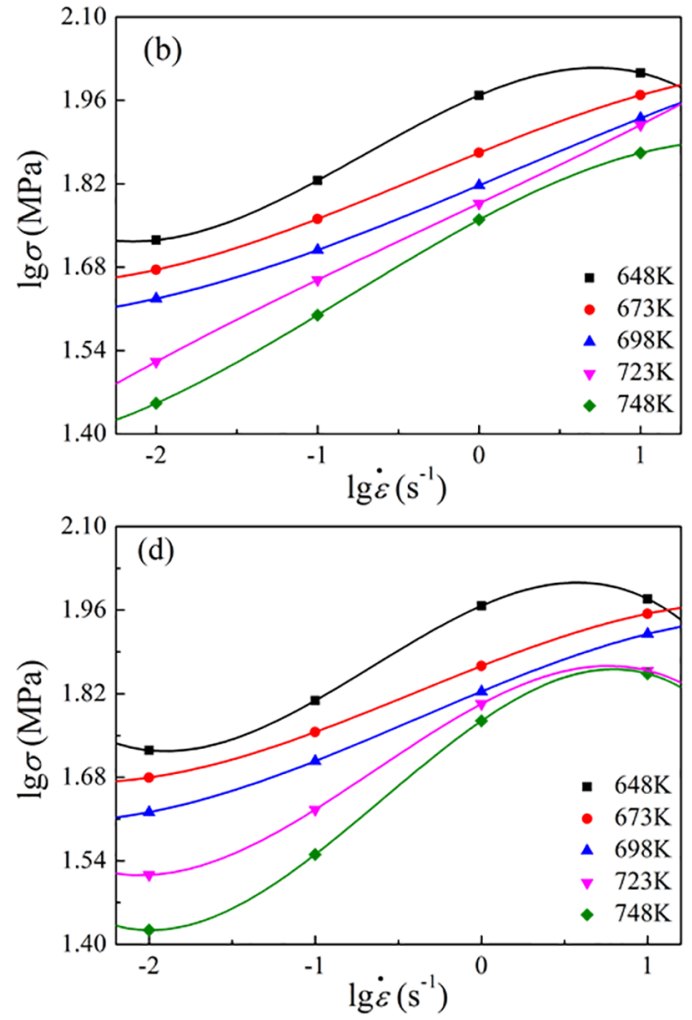

Figure 4. Relationships between stress and strain rate in $\lg$ scale at temperature of $648-748 \mathrm{~K}$ and strain of (a) $\varepsilon=0.3$; (b) $\varepsilon=0.5$;; (c) $\varepsilon=0.7$; (d) $\varepsilon=0.9$.

Table 1. The $m$-values calculated at different forming temperatures, strains and strain rates.

\begin{tabular}{ccccccc}
\hline \multirow{2}{*}{ True strain } & Strain rate $\left(\mathrm{s}^{-1}\right)$ & \multicolumn{5}{c}{ Temperature $(\mathrm{K})$} \\
\cline { 3 - 7 } 0.3 & 0.01 & 0.0658 & 0.0662 & 0.0791 & 0.1316 & 0.0768 \\
& 0.1 & 0.1404 & 0.0993 & 0.0917 & 0.1329 & 0.1763 \\
& 1 & 0.1090 & 0.1118 & 0.1129 & 0.1299 & 0.1625 \\
& 10 & -0.0284 & 0.1035 & 0.1427 & 0.1226 & 0.0353 \\
0.5 & 0.01 & 0.0299 & 0.0550 & 0.0615 & 0.0791 & 0.0384 \\
& 0.1 & 0.1460 & 0.1052 & 0.0987 & 0.1516 & 0.1922 \\
& 1 & 0.1148 & 0.1117 & 0.1141 & 0.1402 & 0.1781 \\
& 10 & -0.0640 & 0.0745 & 0.1077 & 0.0450 & -0.0039 \\
0.7 & 0.01 & 0.0009 & 0.0450 & 0.0528 & 0.0391 & 0.0140 \\
& 0.1 & 0.1516 & 0.1085 & 0.1069 & 0.1656 & 0.2045 \\
& 1 & 0.1190 & 0.1102 & 0.1139 & 0.1464 & 0.1874 \\
& 10 & -0.0968 & 0.0503 & 0.0740 & -0.0184 & -0.0374 \\
& 0.9 & -0.0287 & 0.0404 & 0.0531 & 0.0134 & -0.0025 \\
& 0.1 & 0.1579 & 0.1029 & 0.1097 & 0.1748 & 0.2156 \\
& 1 & 0.1222 & 0.1085 & 0.1149 & 0.1477 & 0.1918 \\
& 10 & -0.1360 & 0.0572 & 0.0688 & -0.0678 & -0.0741 \\
\hline
\end{tabular}




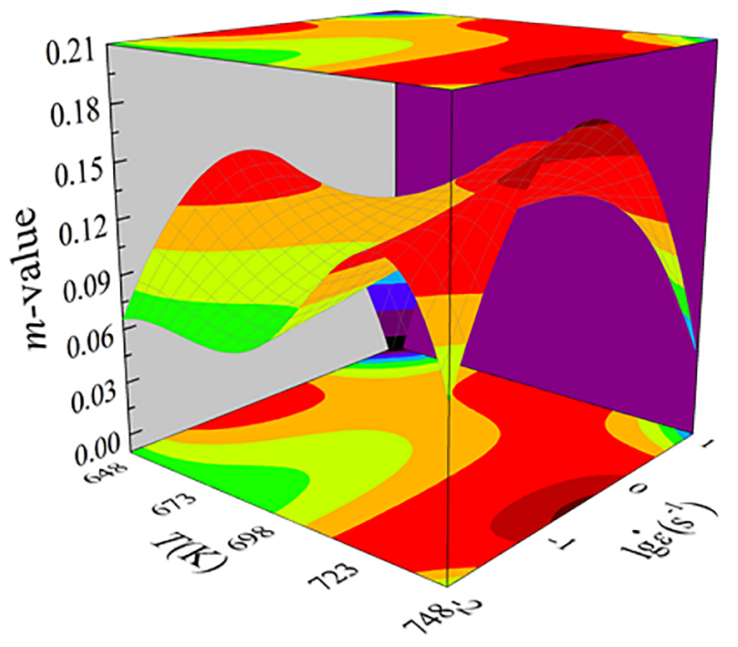

(a)

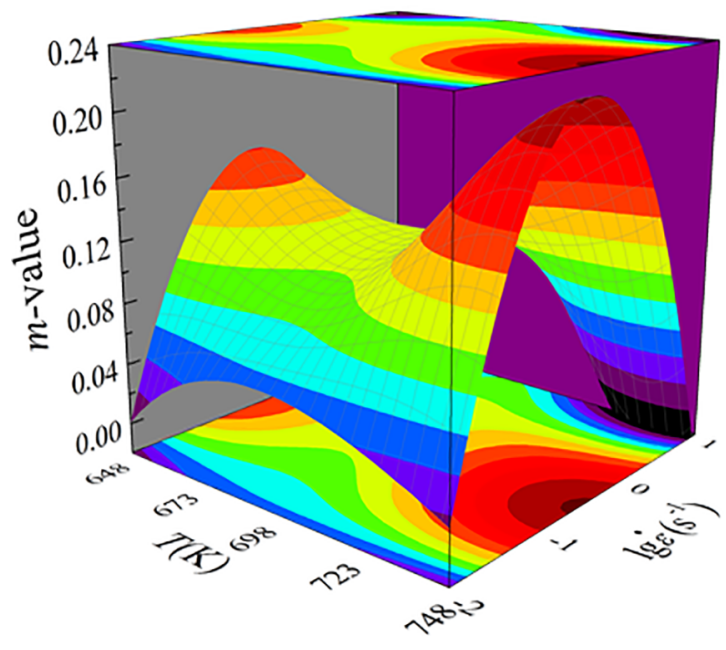

(c)

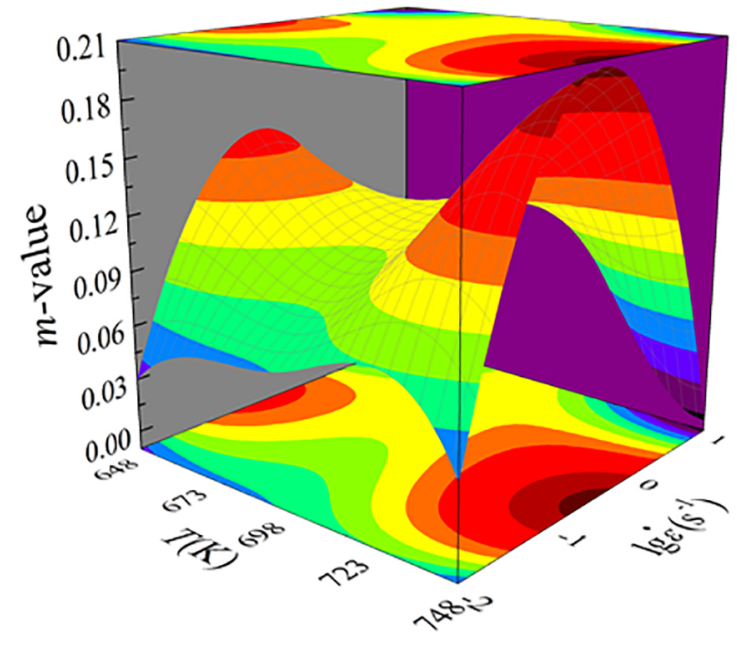

(b)

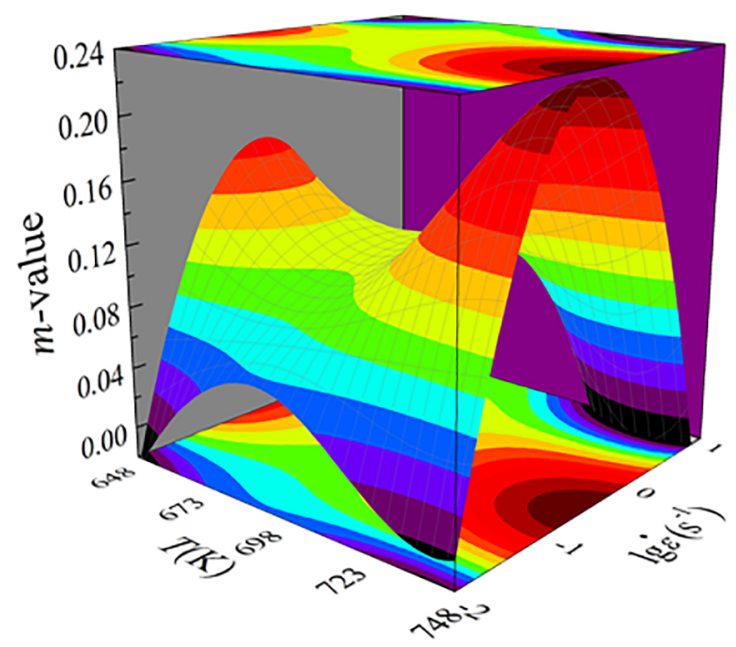

(d)

Figure 5. Response surfaces of $m$-values to temperature and strain rate at true strain of (a) $\varepsilon=0.3$, (b) $\varepsilon=0.5$, (c) $\varepsilon=0.7$ and (d) $\varepsilon=0.9$.

of $\eta$-values, it can be found that the windows including the highest $\eta$-values appeal at relatively higher temperature since non-basal slips are activated which promotes the development of the micro-evolution process. In general, the variation of $m$-values is responsible for the variation of $\eta$-values.

As section 2 described, during a hot deformation process, the power dissipated by work piece in the form of geometric deformation and metallurgical processes. Usually, the high $\eta$-values are advocated because more micro-evolutions occur in the thermal deformation process. However, the higher $\eta$-values do not mean safer plastic flow. For example, the power dissipation coefficient corresponding to cracking forming is generally very high $(>0.5)$, because most energy has been converted into surface energy for the forming and propagation of crack. Therefore, it is necessary to identify the area with stable plastic deformation for as-cast $\mathrm{AlCu} 4 \mathrm{SiMg}$ alloy by constructing the instability maps.

\subsubsection{Instability coefficient $\xi$}

According to Prasad instability criteria, the $\xi$-values were calculated by Eq. (6). The instability maps for as-cast $\mathrm{AlCu} 4 \mathrm{SiMg}$ alloy at true strains of $0.3,0.5,0.7$, and 0.9 were plotted in fig. 7(a)-(d). In the instability maps, negative $\xi$-values marked with grey color represent 


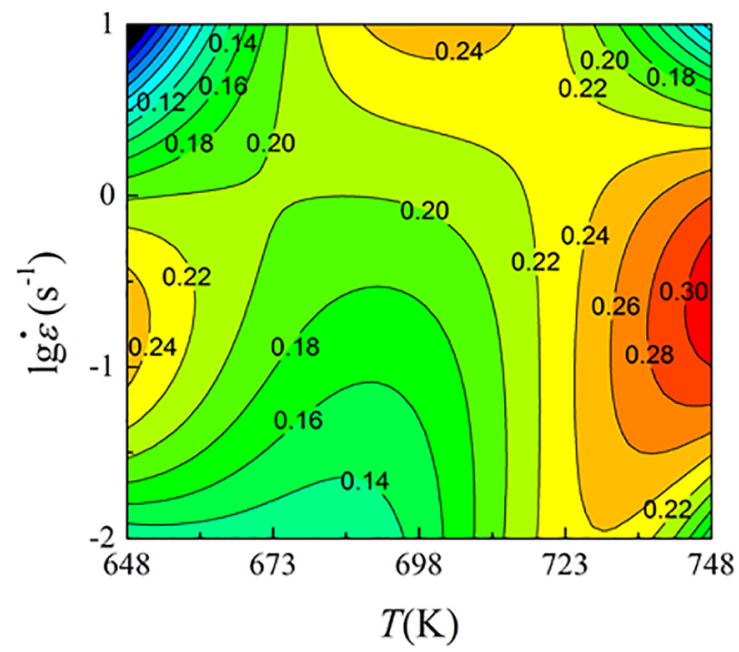

(a)

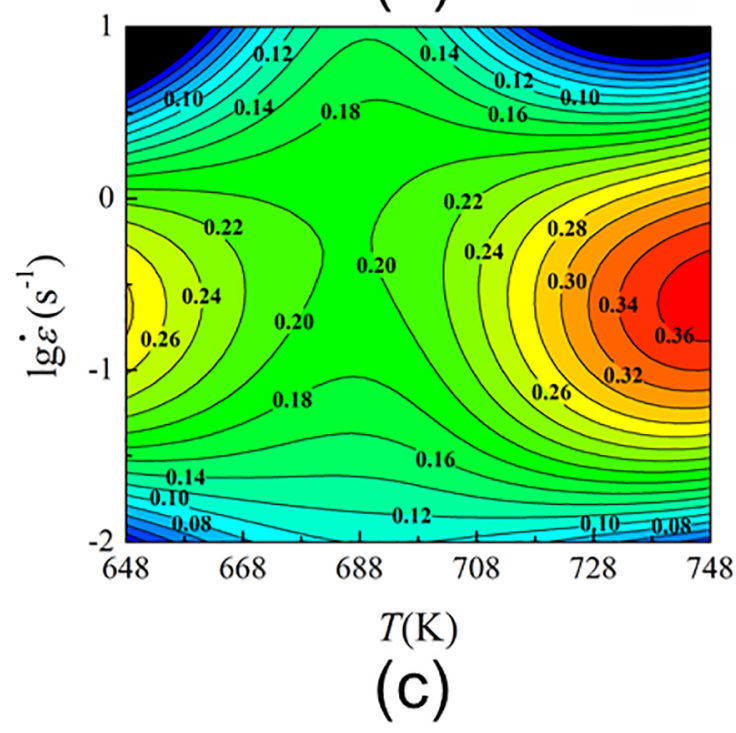

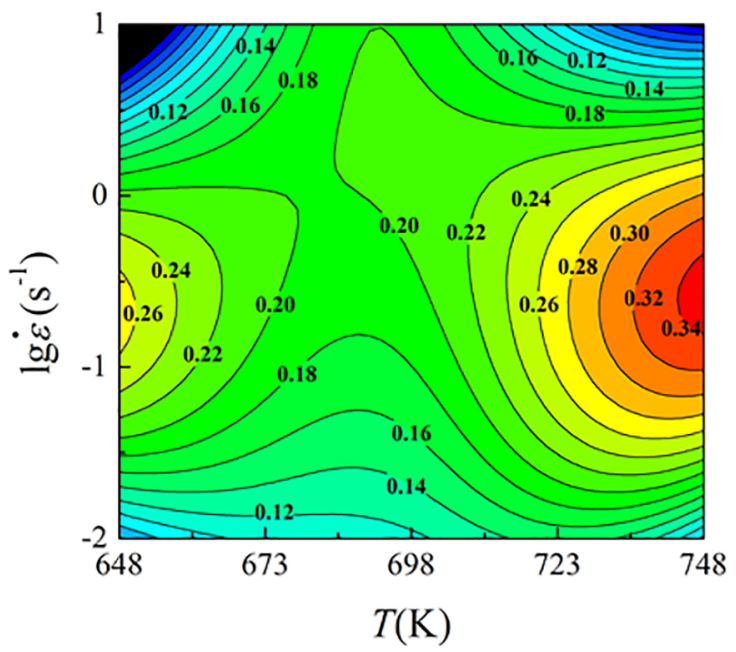

(b)

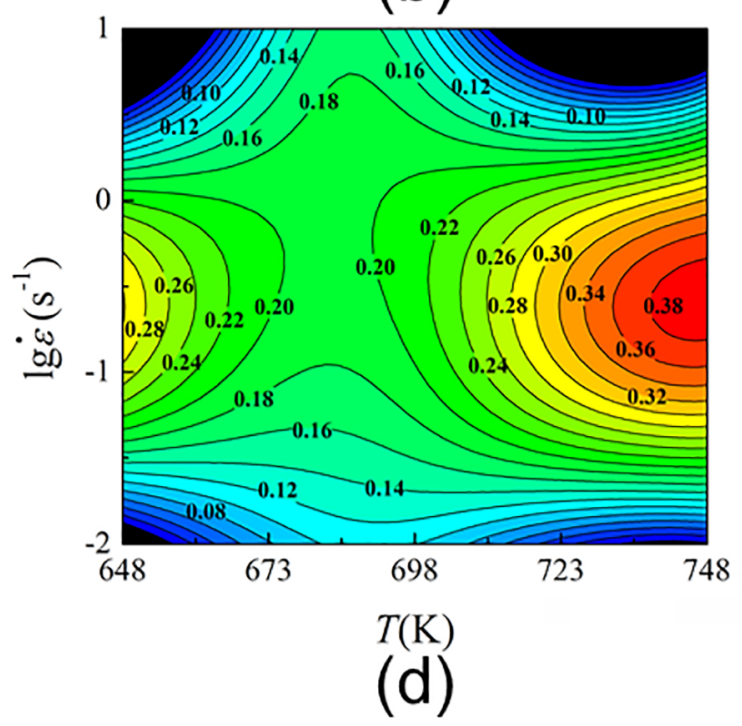

Figure 6. Power dissipation maps at true strain (a) $\varepsilon=0.3$, (b) $\varepsilon=0.5$, (c) $\varepsilon=0.7$ and (d) $\varepsilon=0.9$.

unstable plastic flow. At true strain of 0.3 , there are three instability regions. With true strain increasing, the area of instability regions increases firstly and then decreases. Comparing fig. 6(c) with (d), the instability region at low strain rate and high deformation temperature disappeared when strain increased from 0.7 to 0.9 . In fact, the response of strain rate sensitivity $m$ to thermal processing parameters is fundamentally responsible for the variation of instability coefficient $\xi$. Generally, the regions with negative $m$-value and $\eta$-value are corresponding to unstable plastic deformation. Therefore, it is necessary to identify the stable plastic deformation regions by comprehensively evaluating the strain rate sensitivity $m$, power dissipation coefficient $\eta$, and instability coefficient $\xi$.

\subsubsection{Processing maps for $\mathrm{AlCu} 4 \mathrm{SiMg}$ alloy}

Processing map can not only reveal the microstructural evolution mechanisms but also offer the limiting conditions for stable plastic flow. Besides, it provides optimized hot processing parameter windows corresponding to desired micro-evolution mechanisms. The processing maps for as-cast $\mathrm{AlCu} 4 \mathrm{SiMg}$ alloy at true strains of $0.3,0.5,0.7$, and 0.9 were constructed by superimposing the instability maps over the power dissipation maps, as shown in fig. 8 . In the processing maps, the unsafe processing parameter windows were marked with shadow. In fig. 8, the most desired processing parameter windows corresponding to DRX mechanism appear at relatively high temperature and low strain rate with a higher power dissipation coefficient 


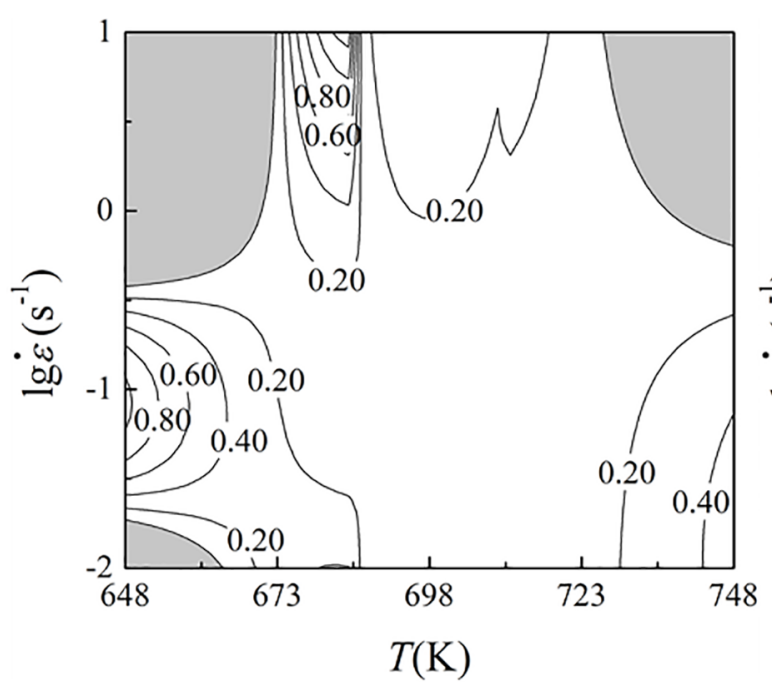

(a)

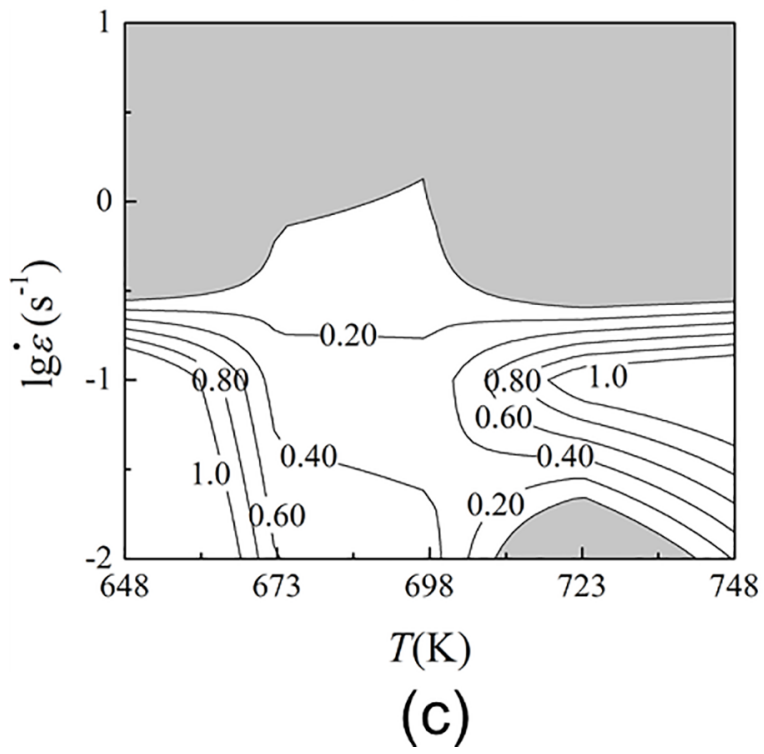

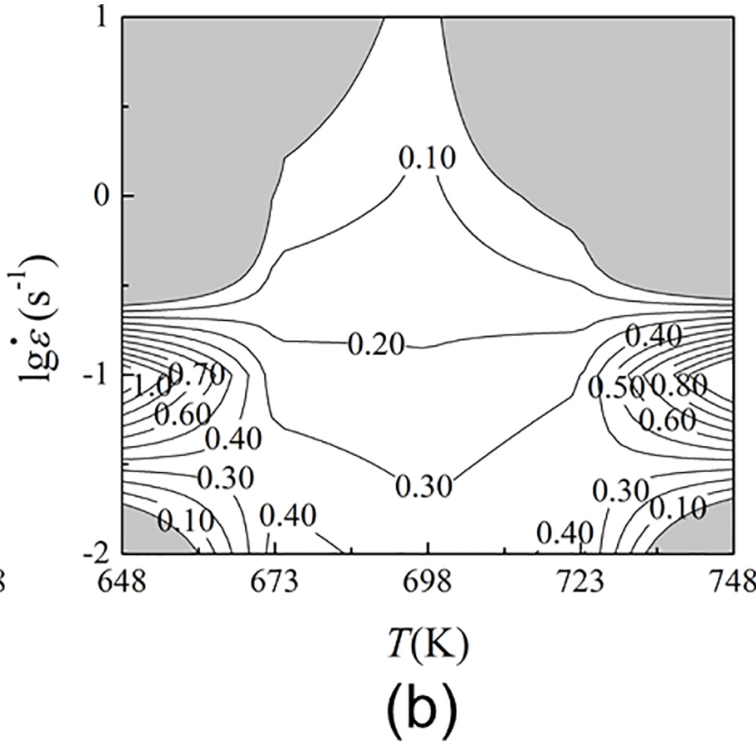

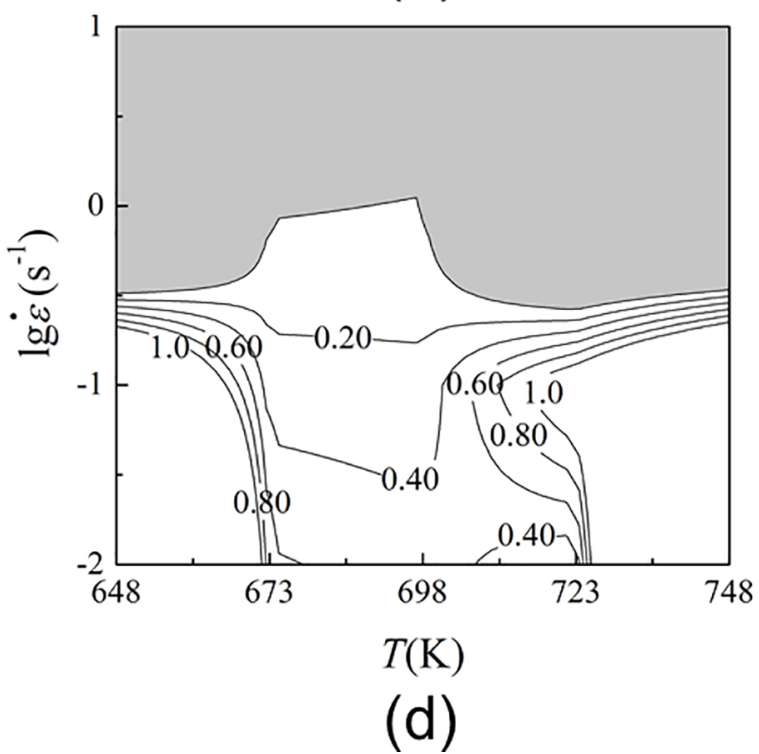

Figure 7. instability maps at true strain of (a) 0.3 , (b) 0.5 , (c) 0.7 and (d) 0.9 .

( $\eta$-values above 0.3 ), marked with red color. In addition, the unstable plastic flow domains mainly appear at relatively high strain rate. With increasing strain, the DRX domains began to expand, and meanwhile, the unstable plastic flow domains are also expanded. According to the processing maps of as-cast $\mathrm{AlCu} 4 \mathrm{SiMg}$ alloy, there are two optional processing domains. One is the DRX domain, the other is the second processing domain located in lower deformation temperature and moderate strain rate corresponding to DRV mechanism.

The distribution of the optimal processing parameter domains for as-cast $\mathrm{AlCu} 4 \mathrm{SiMg}$ alloy is similar to that of Mg-based alloy ${ }^{20}$, i.e., the DRX domains are mainly located in high deformation temperature, and the level of power dissipation coefficient is similar. However, as compared with the processing maps of austenite steels ${ }^{21}$, things are completely different. The optimal processing parameter domains for austenite steel appear at moderate deformation temperature and low strain rate. Such difference comes from the fact that different materials will consume different energy during a hot deformation process, which influences the power partitioning between $\mathrm{G}$ and J. As compared with the processing map of Ni-based alloy ${ }^{22}$, the DRX domains for $\mathrm{AlCu} 4 \mathrm{SiMg}$ alloy are larger, and the level of $\eta$-value is higher, which means that the DRX processes are more obvious for this aluminum alloy. 


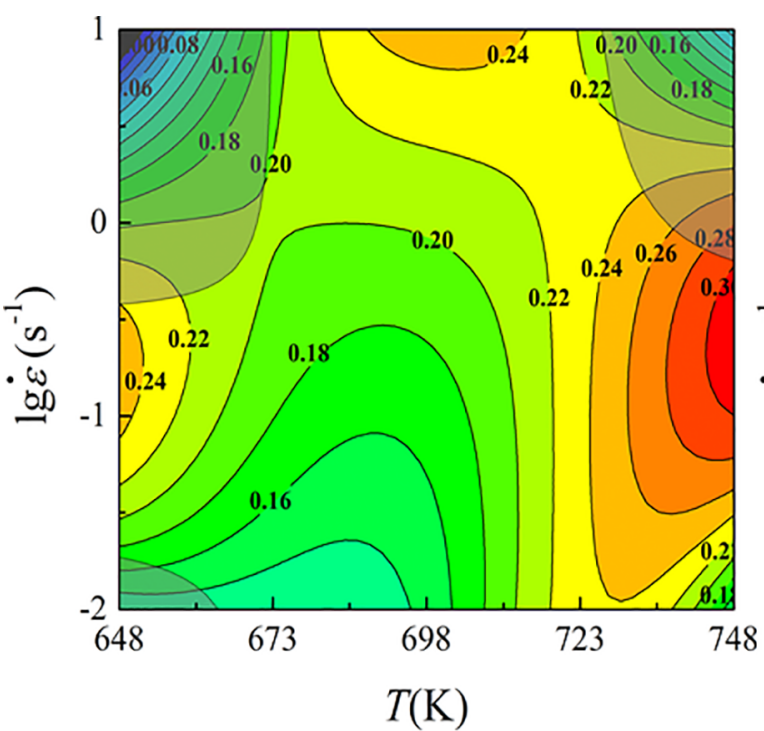

(a)

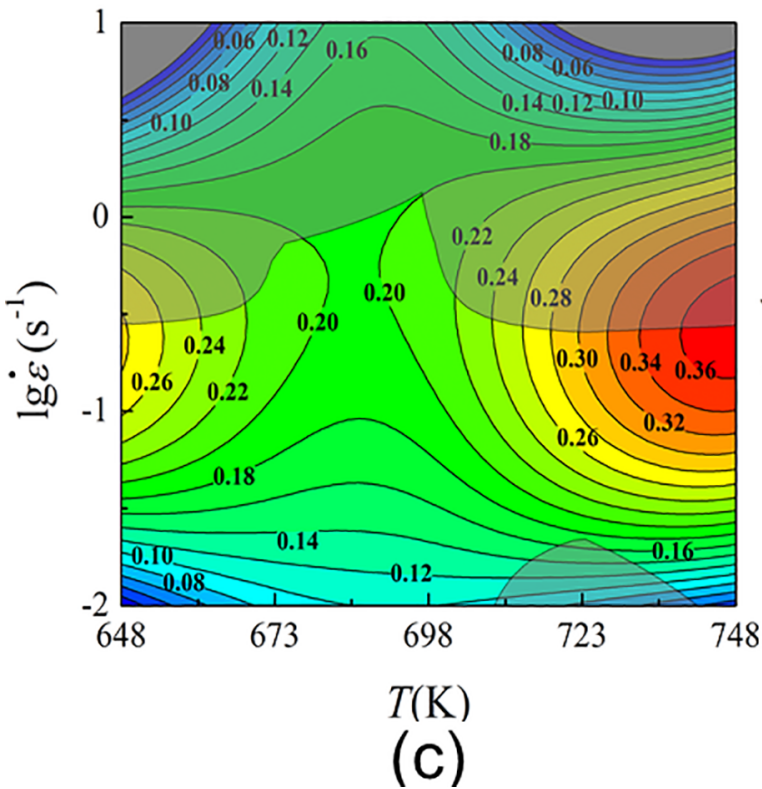

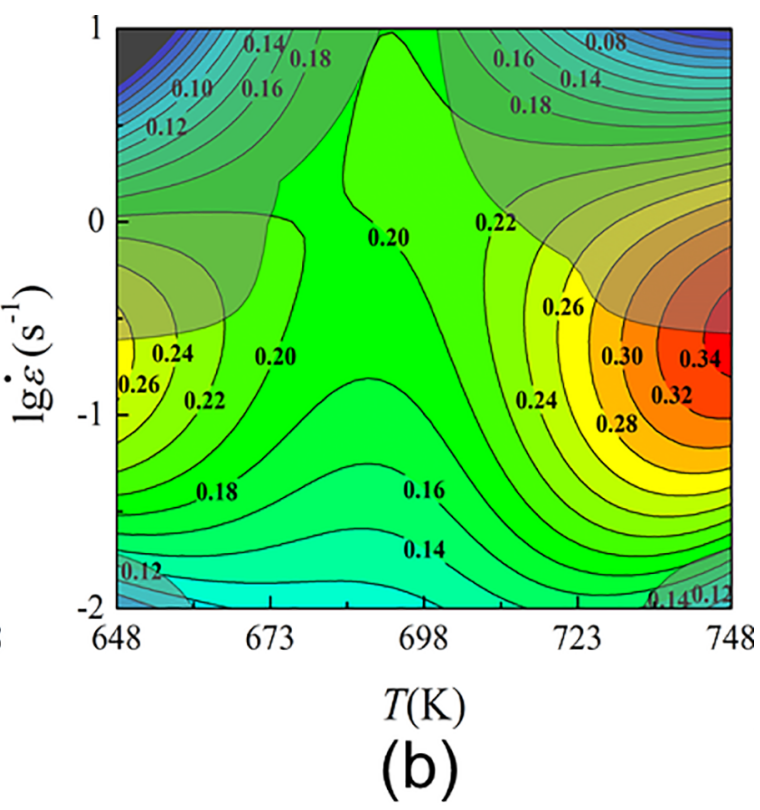

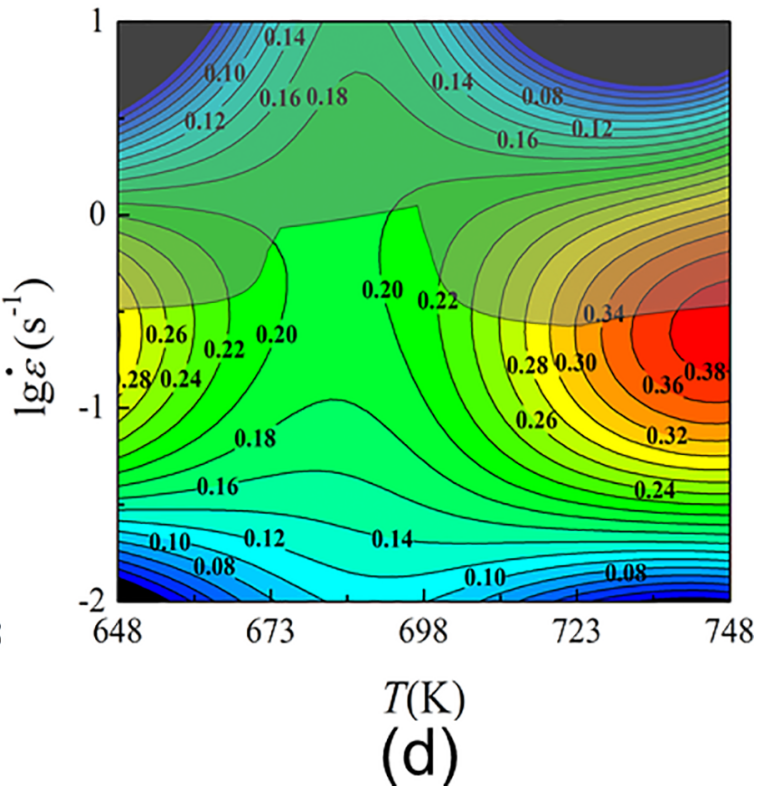

Figure 8. The processing maps for AlCu4SiMg alloy at true strain of (a) 0.3, (b) 0.5, (c) 0.7 and (d) 0.9 .

\subsection{The construction of $Z$ parameter map}

\subsubsection{Calculation of Z-value}

During the hot deformation process of an alloy or metal, the correlation of true stress, temperature and strain rate can be expressed as the following constitutive equations ${ }^{18}$ :

$$
\begin{aligned}
& Z=\dot{\varepsilon} \exp [Q /(R T)] \\
& Z=f_{1}(\sigma)=\mathrm{A}_{1} \sigma^{n_{1}} \quad \alpha \sigma<0.8
\end{aligned}
$$

$$
Z=f_{2}(\sigma)=\mathrm{A}_{2} \exp (\beta \sigma) \quad \alpha \sigma<1.2
$$

$$
Z=f(\sigma)=\mathrm{A}(\sinh \alpha \sigma)^{n} \quad \text { for all } \sigma
$$

Where $Z$ is the Zener-Hollomon parameter. $f(\sigma), f_{1}(\sigma)$ and $f_{2}(\sigma)$ represent the functions of flow stress for an alloy. $\mathrm{A}_{1}, \mathrm{~A}_{2}$, $\mathrm{A}, \beta, n$, and $n_{1}$ are material constants. $\alpha$ is stress multiplier, also the additional adjustable parameter, and $\alpha=\beta / n_{1}{ }^{9} \cdot Q, R$ and $T$ are activation energy, gas constant, absolute temperature, respectively. The power law and the exponent type equation break at a special stress level. The hyperbolic sine equation, also called Arrhenius equation, is suitable for all stress level. 
These material constants can be obtained by means of linear regression. Take the true strain of 0.3 as an example to introduce the solution procedure. First of all, substituting $Z$ with Eq. (7) and taking natural logarithm from both sides of Eq. 8, 9 and 10 yields:

$$
\begin{aligned}
& \ln \dot{\varepsilon}=\ln \mathrm{A}_{1}+n_{1} \ln \sigma-Q /(R T) \\
& \ln \dot{\varepsilon}=\ln \mathrm{A}_{1}+\beta \sigma-Q /(R T) \\
& \ln \dot{\varepsilon}=\ln \mathrm{A}+n \ln \sinh (\alpha \sigma)-Q /(R T)
\end{aligned}
$$

The curves of $\ln \sigma-\ln \varepsilon^{\circ}$ and $\sigma-\ln \varepsilon$ at constant temperatures are plotted in fig. 9(a) and (b). The mean slope of $\ln \sigma-\ln \varepsilon$ and $\sigma-\ln \varepsilon$ are 0.1165 and 7.1035 , respectively. Therefore, $n_{1}=8.5837, \beta=0.1408$. Then, $\alpha=\beta / n_{1}=0.0164$. Subsequently, taking differential transformation of Eq. 13 yields following relation:

$Q=R\left\{\frac{\partial \ln \dot{\varepsilon}}{\partial \ln [\sinh (\alpha \sigma)]}\right\}_{T}\left\{\frac{\partial \ln [\sinh (\alpha \sigma)]}{\partial(1 / T)}\right\}_{\varepsilon}$

At the constant temperatures, the $n$-values were obtained from the slopes of $\ln [\sinh (\alpha \sigma)]$ versus $\ln \varepsilon$ as shown in fig. 9 (c). Meanwhile, the slopes of $\ln [\sinh (\alpha \sigma)]$ versus $1000 / T$ at every constant strain rate were obtained, as shown in Fig. 9(d). Then, $Q$-values at various temperatures and strain rates can be obtained according to Eq. 14, and the average $Q$-value is $172.6268 \mathrm{KJ} / \mathrm{mol}$, which is higher than that of pure aluminum, $142 \mathrm{KJ} / \mathrm{mol}$. Finally, the values of $\ln Z$ at various temperatures and strain rates were calculated according to Eq. (7), and average value of $\ln Z$ is 28.7585. Meanwhile, the $\ln A$-value can be obtained from the intercept of $\ln Z$ versus $\ln [\sinh (\alpha \sigma)]$, as shown in fig. 10. The constant A was calculated as 0.01423 with a correlation coefficient $r=0.98467$.

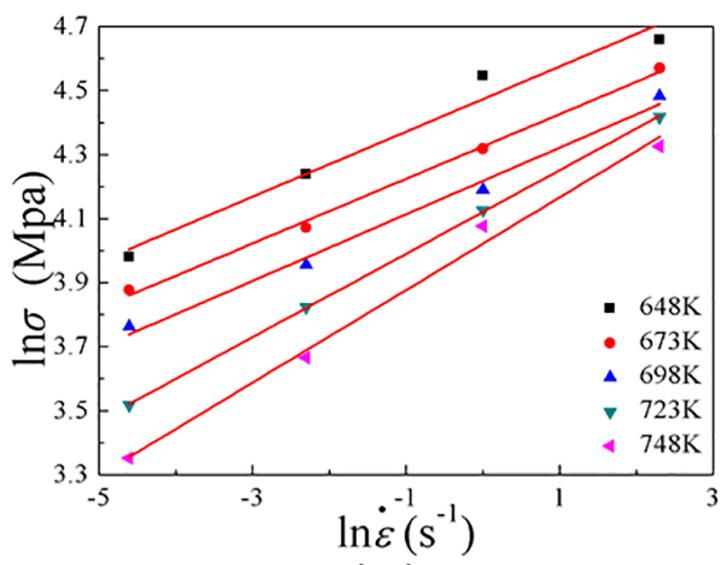

(a)

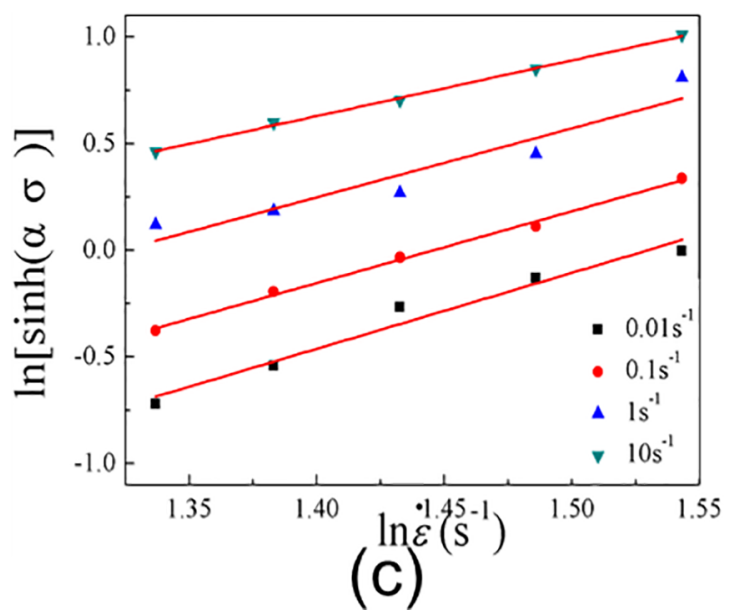

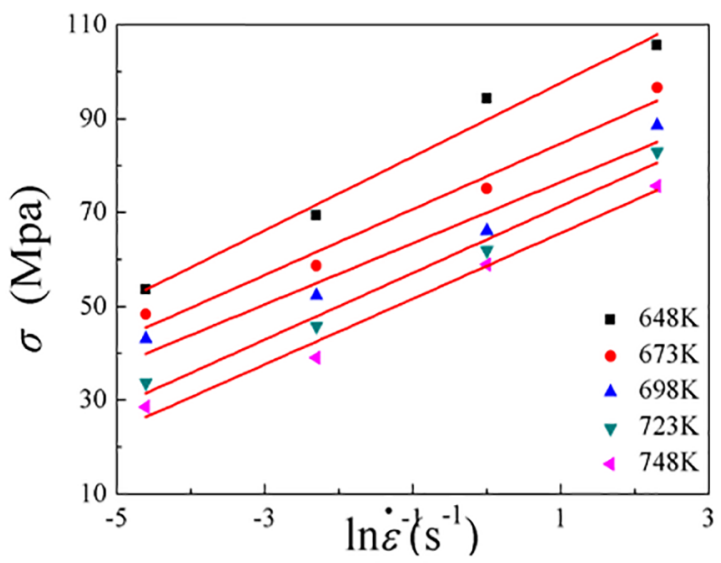

(b)

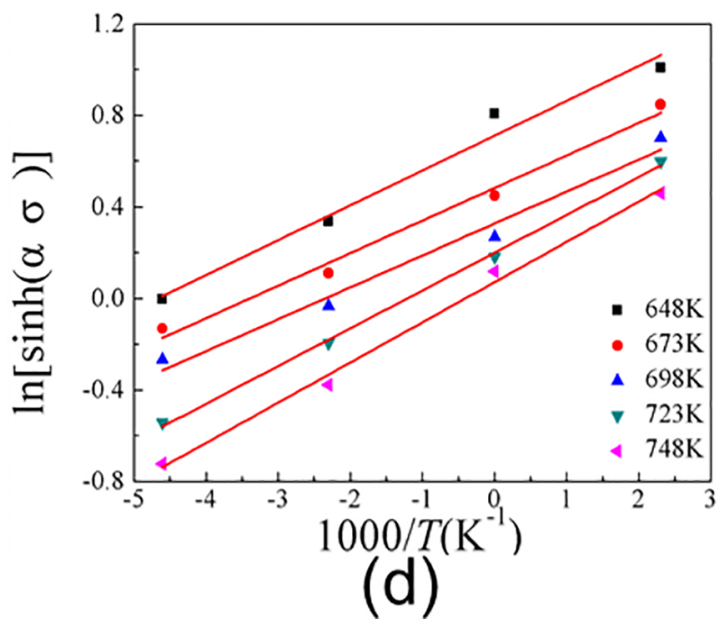

Figure 9. Liner relationships between: (a) $\ln \sigma-\ln \varepsilon ;$, (b) $\sigma-\ln \varepsilon^{;}$, (c) $\ln [\sinh (\alpha \sigma)]-\ln \varepsilon$; and (d) $\ln [\sinh (\alpha \sigma)]-1000 / T$. 


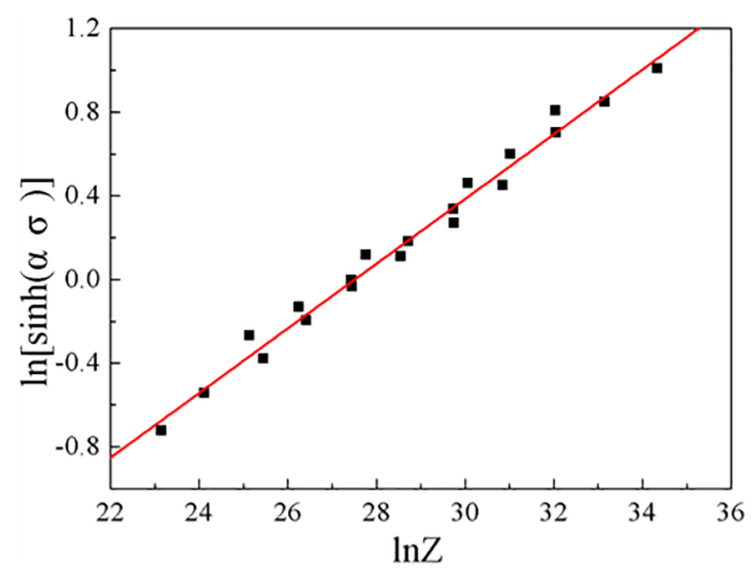

Figure 10. Linear relationship of $\ln [\sinh (\alpha \sigma)]-\ln Z$.

\subsubsection{Z-parameter maps for $\mathrm{AlCu} 4 \mathrm{SiMg}$ alloy}

Zener-Holloman parameter, the temperature-compensated strain rate factor, is closely associated with the dominant softening mechanisms. Thus, the variation of $Z$ parameter is usually applied to analyze the corresponding relationships between micro-evolution mechanisms and deformation conditions. $\mathrm{Z}$ parameter is a direct indicator that used to reflect the level of stress, i.e., softening extent of materials. The main dynamic softening mechanism is DRV and DRX for pure aluminum and most aluminum alloy. In addition, it is generally established that softening mechanism of alloys during high temperature deformation transforms from DRV to DRX with decreasing $Z$ value. For a general aluminum alloy, the main soften mechanism is DRV at high $Z$ value, and DRX is primary soften mechanism when material deformed at low $Z$ value ${ }^{23),(24}$. As for as-cast $\mathrm{AlCu} 4 \mathrm{SiMg}$ alloy, the values of $\ln Z$ under different deformation temperatures, strain rates and true strains were calculated according to the solution procedure introduced in section 4.2.1. Subsequently, the $Z$ parameter maps for $\mathrm{AlCu} 4 \mathrm{SiMg}$ alloy were constructed, as shown in fig. 11. According to the $Z$ parameter maps, the $\ln Z$-value varies in the range of $20 \sim 36$, and the relatively low $\ln Z$-values appear at high deformation temperature. With increasing deformation temperature and strain rate, the $Z$-values intend to be higher. The distribution and level of $Z$-values for AlCu4SiMg alloy are similar to that of AA2195 aluminum alloy ${ }^{25}$. However, the distribution and level of $Z$-values for AlCu4SiMg alloy is largely different from that of $Z$-values for Al alloy (2014)-10 wt.\% SiCp composite $^{26}$. Because of the low content of $\mathrm{SiC}$ composite, the movement of dislocations for $\mathrm{AlCu} 4 \mathrm{SiMg}$ alloy matrix will not be impeded when deformed at high temperature. Hence, for $\mathrm{AlCu} 4 \mathrm{SiMg}$ alloy, the strain rate will have little impact on the change of $\mathrm{Z}$ parameter.
According to reference ${ }^{27}$, the critical $\ln Z$-value that represents the onset of DRX is around 30 for aluminum alloy. Thus, the optimal processing parameter windows corresponding to DRX grain refine mechanism will appear at relatively high deformation temperature, i.e., at the domains with $\ln Z$ less than 30 . However, even if the $\ln Z$-values are less than 30 , it doesn't mean the corresponding processing parameters are expected, because low $\ln Z$-values may be related to the forming of voids. Therefore, metallographic experiment is essential to verify the optimal processing parameters. Additionally, it is significant to compare the processing parameter windows obtained from processing map and $\mathrm{Z}$ parameter map.

\subsection{Integrated deformation mechanism maps}

In order to compare the difference of the optimal parameter windows obtained from the above two methods, the integrated deformation mechanism maps for as-cast $\mathrm{AlCu} 4 \mathrm{SiMg}$ alloy have been constructed by superimposing the $Z$ parameter maps on processing map, as shown in fig. 12. In fig. 12, red represents DRX domain identified by processing map; green represents DRV domain identified by processing map; shadow represents unstable plastic flow domain; the black line represents the critical $\ln Z$ value $(\ln Z=30)$. According to fig. 12 , the optimal hot processing parameter windows identified by $Z$ parameter map include the DRX domains and a part of unstable deformation domains that identified by processing map. According to the integrated deformation mechanism maps, the optimal hot processing parameter windows mainly appear at high deformation temperature and moderate strain rate. With increasing deformation temperature, the deformation resistance reduces and micro-evolution became severer. As true strain increases, the windows identified by $\mathrm{Z}$ parameter shrink to high-temperature domains, and the windows identified by processing maps begin to expand. Finally, as the true strain of 0.9 , the windows identified by the two methods basically coincide. This result is originated from the different softening model at different strain level. At low true strain, the main softening model is thermal softening. At relatively high true strain, the material softening is mainly originated from the occurrence of DRX. It is well known that $\mathrm{Z}$ parameter is closely related to material softening. At high true strain, the impact of thermal softening can be ignored when it compared with the impact of micro-evolution. Therefore, as true strain increases, the result that obtained from the two methods tends to be consistent. In order to reveal the interior difference of the optimal parameter windows obtained from the above two methods as well as to deeply understand the thermal deformation mechanism of $\mathrm{AlCu} 4 \mathrm{SiMg}$ alloy, metallographic observations are essential. 

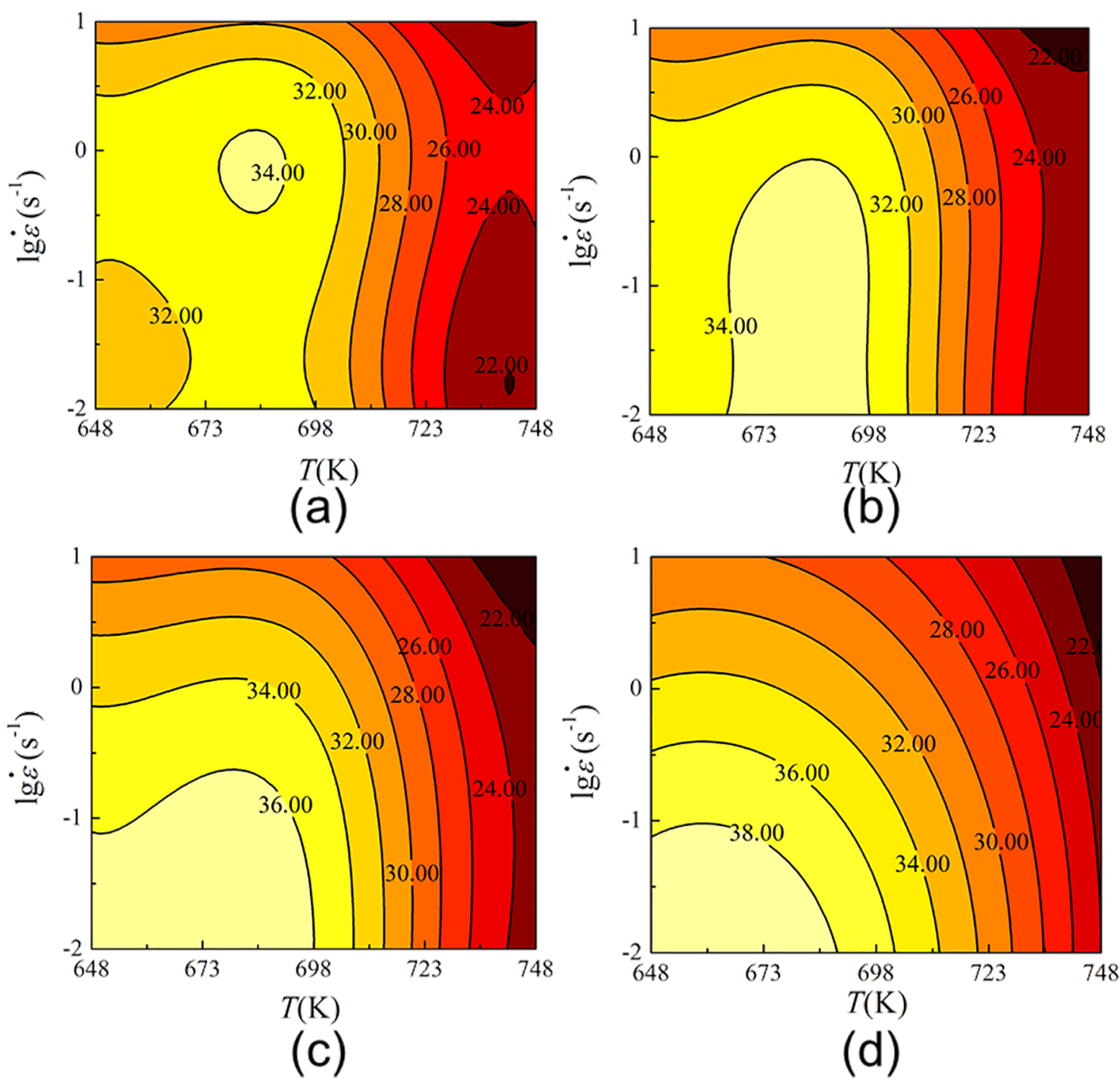

Figure 11. The $Z$ parameter maps for as-cast AlCu4SiMg alloy at true strain of (a) 0.3 , (b) 0.5 , (c) 0.7 and (d) 0.9 .

Fig. 13 reveals the microstructures of specimens deformed under different processing parameters. In fig. 13(a), uniform and deformed grains can be observed clearly, which means DRV is the main micro-evolution mechanism. Besides, a small amount of DRX grains appear at the grain boundaries. This result validates the DRV domains identified by processing map. In fig. 13(b), uneven plastic deformation can be observed. Only the central domains have plastic flow, and the edge areas have no plastic deformation. Therefore, the ASB was formed at the junction of the deformed and undeformed domains. It is the major instability mechanism when specimens deformed at low deformation temperature. In fig. 13(c), fine grains appear at original grain boundaries.
It means that partial DRX mechanism is the major microevolution mechanism. In fig. 13(d), elongated grains can be observed, and meanwhile, cavities can also be observed clearly, which represents the micro-evolution mechanism is DRV and formation of cavities. Formation of cavities is the main instability mechanism when specimens deformed at high deformation temperature. In fig. 13(e), fine and uniform equiaxed grains are obtained, which means full DRV is the major micro-evolution mechanism.

By comprehensively analyzing the results of microstructure observations and the integrated deformation mechanism maps, a deep cognition of the deformation mechanism maps can be achieved. The DRV, DRX, and unstable plastic 


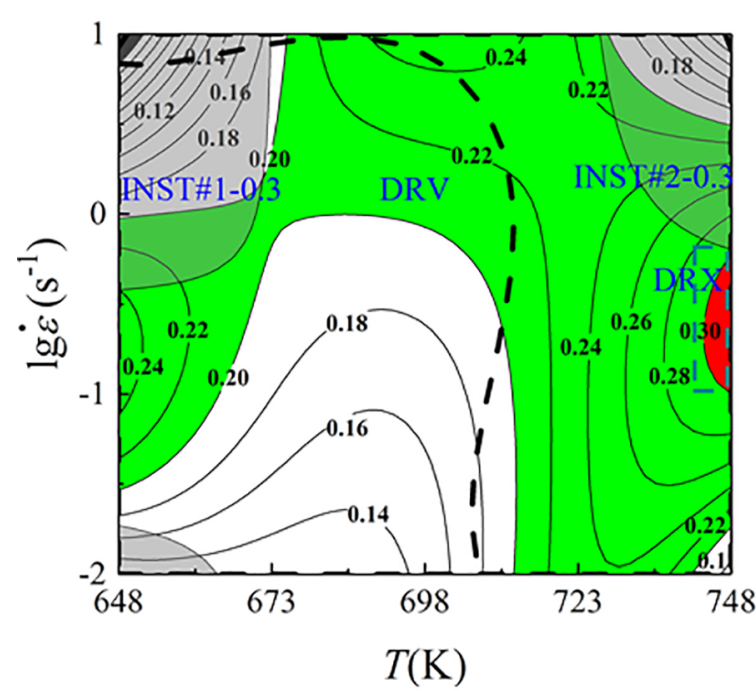

(a)

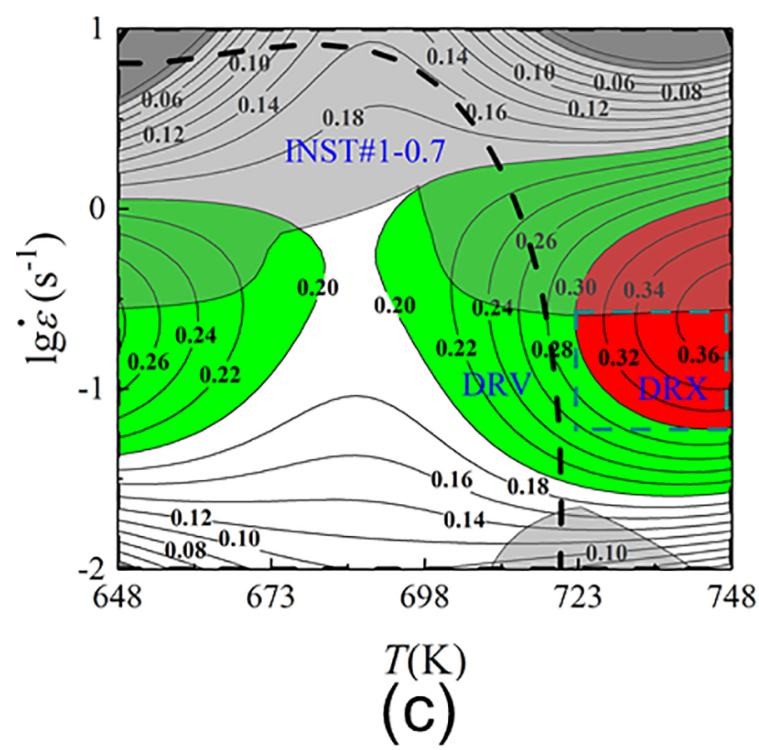

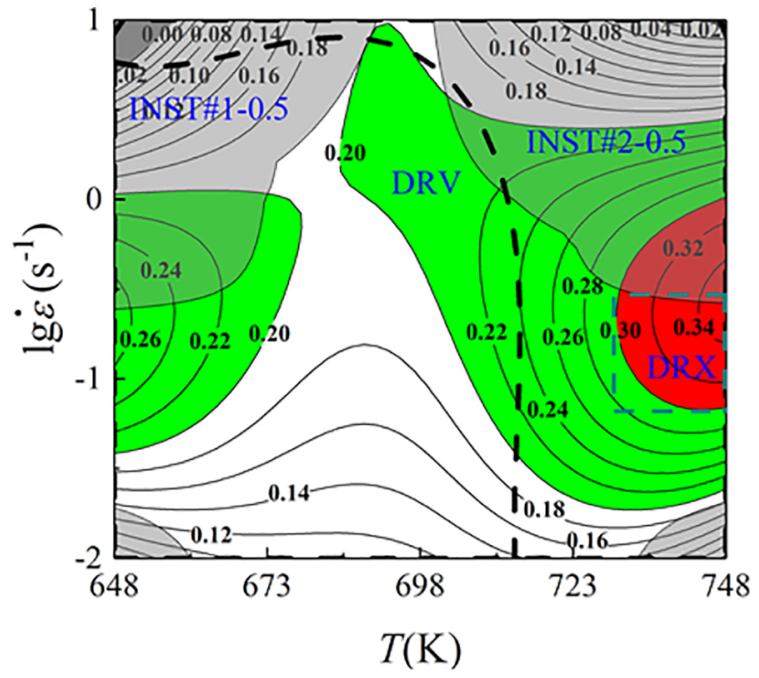

(b)

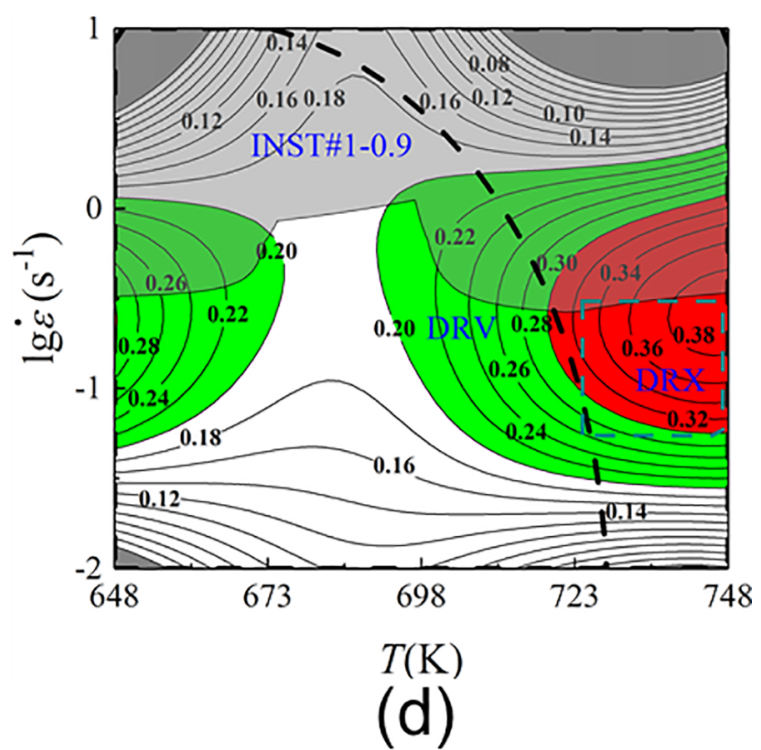

Figure 12. The integrated deformation mechanism maps for as-cast $\mathrm{AlCu} 4 \mathrm{SiMg}$ alloy at true strain of (a) 0.3 , (b) 0.5 , (c) 0.7 and (d) 0.9 . 

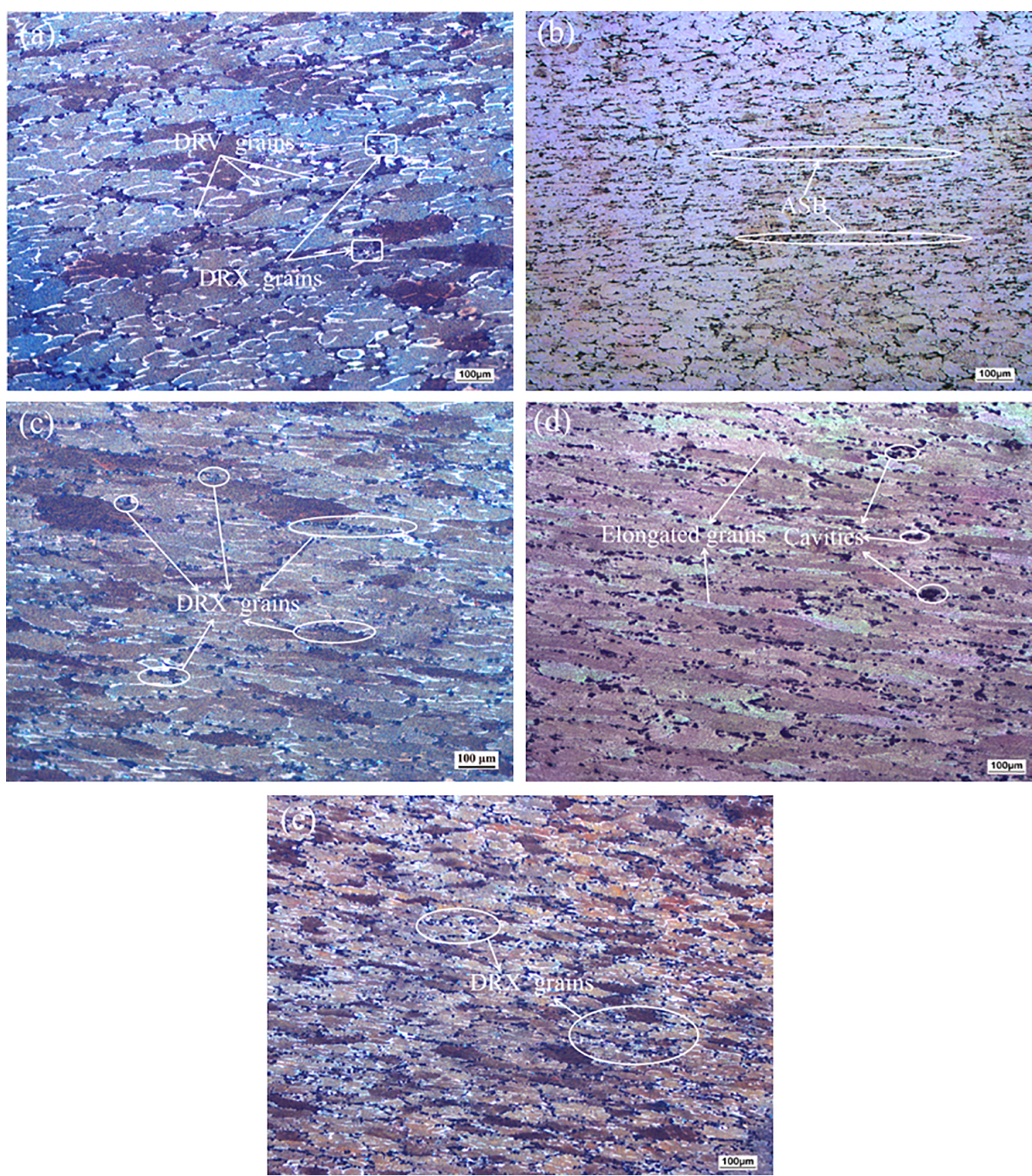

Figure 13. Microstructures of the specimens deformed at different conditions (a) $648 \mathrm{~K}, 0.1 \mathrm{~s}^{-1}$; (b) $648 \mathrm{~K}, 1 \mathrm{~s}^{-1}$; (c) $723 \mathrm{~K}, 0.1 \mathrm{~s}^{-1}$; (d) $723 \mathrm{~K}, 1 \mathrm{~s}^{-1}$; (e) $748 \mathrm{~K}, 0.1 \mathrm{~s}^{-1}$. 
deformation domains identified by processing maps have been validated by microstructure observations. The optimal processing windows classified by $Z$ parameter consists of DRX domains and a part of unstable plastic flow domains. It is well known that $Z$ parameter is a direct index used to reflect the level of stress, as described in Eq. 10. Thus, the lower $\ln Z$-value will be associated with the forming of cavities or the DRX softening mechanism. Anyway, when deformed at low $\ln Z$-value, the required force will be lower. Therefore, although two optional processing parameter domains have been obtained in processing maps, the processing parameter domains with relatively low $\ln Z$-value will be a better choice. In general, the optimal processing parameter windows with low forming force and DRX grain refine mechanism can be clearly classified. As for the as-cast AlCu4SiMg alloy, the optimal thermal processing parameter windows have been obtained by evaluating the integrated deformation mechanism maps.

\section{Conclusions}

In this study, the thermal deformation mechanisms for as-cast $\mathrm{AlCu} 4 \mathrm{SiMg}$ alloy were investigated by isothermal compression experiments and microstructural observations. And the following conclusions can be drawn.

(1) The processing maps for as-cast $\mathrm{AlCu} 4 \mathrm{SiMg}$ alloy were developed based on DMM. The safe processing parameter windows with stable plastic flow were distinguished from a wide range of processing parameters. Further, in the safe domains, the DRX windows and DRV windows were identified based on the level of $\eta$-values.

(2) The $Z$ parameter maps for as-cast $\mathrm{AlCu} 4 \mathrm{SiMg}$ alloy were constructed at true strain of $0.3,0.5,0.7$ and 0.9 . The optimal processing window identified by $Z$ parameter is more conservative than that identified by processing map.

(3) The optimal thermal processing parameters for as-cast $\mathrm{AlCu} 4 \mathrm{SiMg}$ alloy corresponding to DRX grain refinement mechanism were identified by integrating processing maps with $Z$ parameter maps. The windows are as follows: $\varepsilon=0.3$, window: temperature of $741-748 \mathrm{~K}$ and strain rate of $0.10-0.70 \mathrm{~s}^{-1}$. $\varepsilon=0.5$, window: temperature of $730-748 \mathrm{~K}$ and strain rate of $0.07-0.29 \mathrm{~s}^{-1}$. $\varepsilon=0.7$, window: temperature of $721-748 \mathrm{~K}$ and strain rate of $0.06-3.45 \mathrm{~s}^{-1}$. $\varepsilon=0.9$, window: temperature of $723-748 \mathrm{~K}$ and strain rate of $0.06-0.29 \mathrm{~s}^{-1}$.

\section{Acknowledgement}

The work was supported by Chongqing Foundation and Frontier Research Project (cstc2016jcyjA0335), Open Fund Project of State Key Laboratory of Materials Processing and Die \& Mould Technology (No. P2017-020), and Research Project of State Key Laboratory of Mechanical Transmission (No. SKLMT-ZZKT-2017M15).

\section{References}

1. Ajeet Babu PK, Saraf MR, Vora KC, Chaurasiya SM, Kuppan P. Influence of Forging Parameters on the Mechanical Behavior and Hot Forgeability of Aluminium Alloy. MaterialsToday: Proceedings. 2015;2(4-5):3238-3244.

2. Driver J. The limitations of continuous dynamic recrystallization (CDRX) of aluminium alloys. Materials Letters. 2018;222:135137.

3. Dhal A, Panigrahi SK, Shunmugam MS. Precipitation phenomena, thermal stability and grain growth kinetics in an ultra-fine grained Al 2014 alloy after annealing treatment. Journal of Alloys and Compounds. 2015;649:229-238.

4. Liang XP, Li HZ, Huang L, Hong T, Ma B, Liu Y. Microstructural evolution of 2519-T87 aluminum alloy obliquely impacted by projectile with velocity of $816 \mathrm{~m} / \mathrm{s}$. Transactions of Nonferrous Metals Society of China. 2012;22(6):1270-1279.

5. Charpentier PL, Stone BC, Ernst SC, Thomas JF. Characterization and modeling of the high temperature flow behavior of aluminum alloy 2024. Metallurgical Transactions A. 1986;17(12):22272237.

6. Gavgali M, Aksakal B. Effects of various homogenisation treatments on the hot workability of ingot aluminium alloy AA2014. Materials Science and Engineering: A. 1998;254(12):189-199.

7. Du ZH, Jiang SS, Zhang KF. The hot deformation behavior and processing map of Ti-47.5Al-Cr-V alloy. Materials \& Design. 2015;86:464-473.

8. Wang G, Xu L, Wang Y, Zheng Z, Cui YY, Yang R. Processing Maps for Hot Working Behavior of a PM TiAl Alloy. Journal of Materials Science \& Technology. 2011;27(10):893-898.

9. Dong YY, Zhang CS, Zhao GQ, Guan YJ, Gao AJ, Sun WC. Constitutive equation and processing maps of an $\mathrm{Al}-\mathrm{Mg}-\mathrm{Si}$ aluminum alloy: Determination and application in simulating extrusion process of complex profiles. Materials \& Design. 2016;92:983-997.

10. Park SY, Kim WJ. Difference in the Hot Compressive Behavior and Processing Maps between the As-cast and Homogenized Al-Zn-Mg-Cu (7075) Alloys. Journal of Materials Science \& Technology. 2016;32(7):660-670. 
11. Fang B, Ji Z, Liu M, Tian GF, Jia CC, Zeng TT, et al. Study on constitutive relationships and processing maps for FGH96 alloy during two-pass hot deformation. Materials Science and Engineering: A. 2014;590:255-261.

12. Shi ZX, Yan XF, Duan CH. Characterization of hot deformation behavior of GH925 superalloy using constitutive equation, processing map and microstructure observation. Journal of Alloys and Compounds. 2015;652:30-38.

13. Sun Y, Wan ZP, Hu LX, Ren JS. Characterization of hot processing parameters of powder metallurgy TiAl-based alloy based on the activation energy map and processing map. Materials \& Design. 2015;86:922-932.

14. Wang MJ, Wang WR, Liu ZL, Sun CY, Qian LY. Hot workability integrating processing and activation energy maps of Inconel 740 superalloy. MaterialsToday Communications. 2018;14:188198.

15. Jafari M, Najafizadeh A. Correlation between Zener-Hollomon parameter and necklace DRX during hot deformation of 316 stainless steel. Materials Science and Engineering: $A$. 2009;501(1-2):16-25.

16. Huang XD, Zhang H, Han Y, Wu WX, Chen JH. Hot deformation behavior of 2026 aluminum alloy during compression at elevated temperature. Materials Science and Engineering: $A$. 2010;527(3):485-490.

17. Eleti RR, Bhattacharjee T, Zhao LJ, Bhattacharjee PP, Tsuji N. Hot deformation behavior of CoCrFeMnNi FCC high entropy alloy. Materials Chemistry and Physics. 2018;210:176-186.

18. Ji GL, Li FG, Li QH, Li HQ, Li Z. A comparative study on Arrhenius-type constitutive model and artificial neural network model to predict high-temperature deformation behaviour in Aermet100 steel. Materials Science and Engineering: A. 2011;528(13-14):4774-4782.
19. Quan GZ, Zhang L, Wang X, Li YI. Correspondence between microstructural evolution mechanisms and hot processing parameters for Ti-13Nb-13Zr biomedical alloy in comprehensive processing maps. Journal of Alloys and Compounds. 2017;698:178-193.

20. Cheng WL, Bai Y, Ma S, Wang L, Wang H, Yu H. Hot deformation behavior and workability characteristic of a fine-grained Mgnul18Snnull2Znnull2Al alloy with processing map. Journal of Materials Science \& Technology. 2018;34(11):2035-2041.

21. Zhou YH, Liu YC, Zhou XS, Liu CX, Yu JX, Huang Y, et al. Precipitation and hot deformation behavior of austenitic heat-resistant steels: A review. Journal of Materials Science \& Technology. 2017;33(12):1448-1456.

22. Wu YT, Liu YC, Li C, Xia XC, Huang Y, Li HJ, et al. Deformation behavior and processing maps of $\mathrm{Ni}_{3} \mathrm{Al}$-based superalloy during isothermal hot compression. Journal of Alloys and Compounds. 2017;712:687-695.

23. Meng G, Li BL, Li HM, Huang H, Nie Z. Hot deformation behavior of an Al-5.7 wt.\%Mg alloy with erbium. Materials Science and Engineering: A. 2009;516(1-2):131-137.

24. Hu HE, Zhen L, Yang L, Shao WZ, Zhang BY. Deformation behavior and microstructure evolution of 7050 aluminum alloy during high temperature deformation. Materials Science and Engineering: A. 2008;488(1-2):64-71.

25. Yang QB, Wang XZ, Li X, Deng ZH, Jia ZH, Zhang ZQ, et al. Hot deformation behavior and microstructure of AA2195 alloy under plane strain compression. Materials Characterization. 2017;131:500-507.

26. Patel A, Das S, Prasad BK. Compressive deformation behaviour of Al alloy (2014)-10 wt.\% SiCp composite: Effects of strain rates and temperatures. Materials Science and Engineering. A. 2011;530:225-232.

27. Liu XY, Pan QL, He YB, Li WB, Liang WJ, Yin ZM. Flow behavior and microstructural evolution of $\mathrm{Al}-\mathrm{Cu}-\mathrm{Mg}-\mathrm{Ag}$ alloy during hot compression deformation. Materials Science and Engineering: A. 2009;500(1-2):150-154. 